\title{
AN ORTHOTROPIC DAMAGE MODEL FOR THE ANALYSIS OF MASONRY STRUCTURES
}

\author{
Luca Pelà $^{a^{*}}$, Miguel Cervera ${ }^{a}$, Pere Roca ${ }^{a}$ \\ ${ }^{a}$ Technical University of Catalonia (UPC), Campus Norte, Jordi Girona 1-3, 08034 \\ Barcelona, Spain.
}

\begin{abstract}
This paper presents a numerical model for nonlinear analysis of masonry structural elements based on Continuum Damage Mechanics. The material is described at the macro-level, i.e. it is modelled as a homogeneous orthotropic continuum. The orthotropic behaviour is simulated by means of an original methodology, resulting from the concept of mapped tensors from the anisotropic field to an auxiliary workspace. The application of this idea to strain-based Continuum Damage Models is innovative and leads to several computational benefits. The suitability of the model for representing the behaviour of different types of brickwork masonry is shown via the simulation of experimental tests.
\end{abstract}

Keywords: Continuum Damage Mechanics, Orthotropy, Mapping, Transformation Tensor, Masonry, FE analysis, Tensile Cracking.

\section{Introduction}

The assessment of the structural capacity of masonry constructions is still a challenging task. Numerical approaches offer interesting possibilities to deal with such a difficult problem. At present, several methods and computational tools are available for the assessment of the structural behaviour [1] and the choice by the analyst depends on the searched information (serviceability, damage, collapse, failure mechanisms, etc.), the required level of accuracy (local or global behaviour of the structure), the necessary input data (detailed or rough information about material characteristics) and the computational cost (processing time and memory requirements for the analysis). Therefore, trying to individuate a unique model of general validity is not realistic.

\footnotetext{
* Corresponding author.

E-mail addresses: luca.pela@upc.edu (Luca Pelà), miguel.cervera@upc.edu (Miguel Cervera), pere.roca.fabregat@upc.edu (Pere Roca).
} 
Simplified modelling of masonry structures through the equivalent frame method [2] or two-dimensional macro-elements [3] ensures efficient computations, due to drastic reduction of the structure degrees of freedom, but provides only an approximate description of the masonry element behaviour. Contrariwise, micro-modelling [4-5] is considered the most accurate tool available to analyse masonry, since the discretization is carried down to the level of the constituents, viz. unit (brick, block, etc.), mortar and their mutual interfaces. Such high level of refinement requires intensive computational effort, which limits today's micro-models applicability to the analysis of small elements (e.g. laboratory specimens) or to structural details.

Macro-modelling is a valuable approach in practice-oriented analyses, where a compromise between accuracy and efficiency is needed. The material is regarded as a homogeneous orthotropic continuum and this implies considerable computational advantages due to reduced time and memory requirements as well as a user-friendly mesh generation. The mechanical behaviour of the continuum can be described by Plasticity or Continuum Damage Mechanics (CDM) constitutive laws. Macro-models

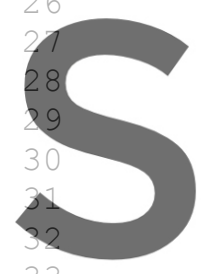
have been extensively used with the gim of a
masonry structures, such as arch bridges [6],
In the case of CDM finite element model
because of their smplicity and the need fo
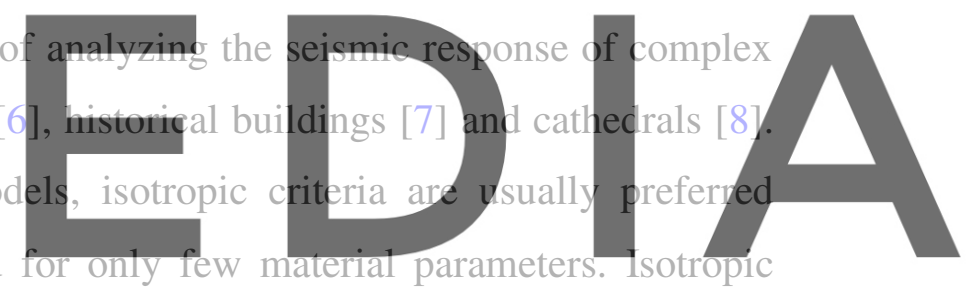

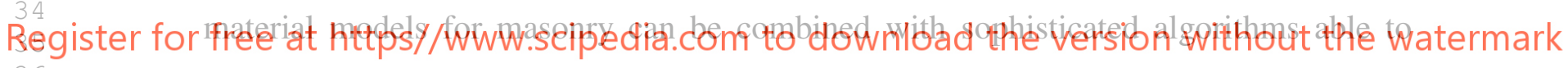
account for cracking localization and to achieve proper structural failure mechanisms [9].

The orthotropic macroscopic behaviour of masonry arises from the spatial organization of its constituents, their nature and the complex units-mortar interaction. Also, masonry exhibits geometrical irregularities in the form of weak planes along the bed and head joints. The degree of anisotropy may increase due to the presence of horizontal or vertical openings in blocks or bricks.

According to the macro-modelling strategy, an appropriate relationship is established between average strains and stresses. The continuum parameters can be assessed by means of tests on specimens of sufficiently large size, under homogeneous states of stress, see for instance [10]. As an alternative to difficult laboratory tests, it is possible to assess experimentally the individual components or simple wallets and cores [11] and consider the obtained data as input parameters for numerical homogenization techniques [12]. 
Several failure criteria have been proposed [13-18] as phenomenological formulations

proposed in Refs. [10,23] considers the principal directions of damage fixed and aligned with the initial orthotropy axes. In tension an exponential softening law for the stressstrain diagrams is adopted, with different fracture energies along each material axes. In
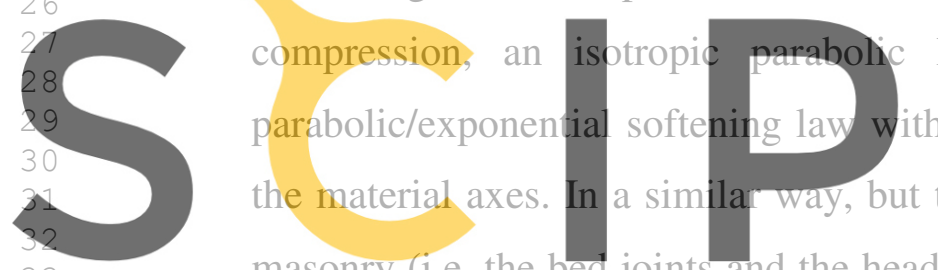

masonry (i.e. the bed joints and the head join
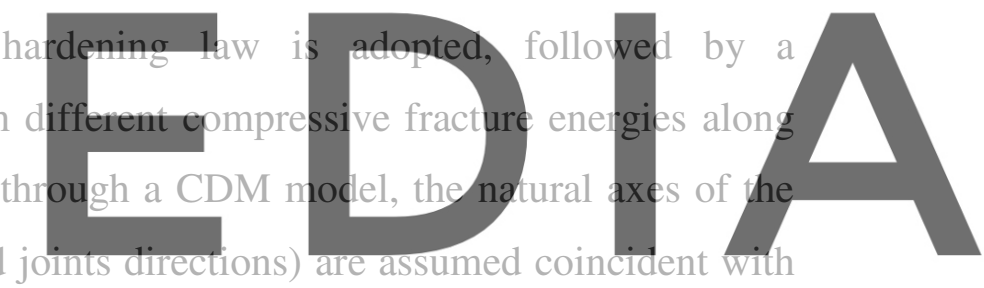

\section{Begister for} based on the interpretations of comprehensive experimental tests. The difficulties in defining reliable and accurate surfaces for the description of the shape of the admissible field have been evident since the first attempts [19]. In spite of the mentioned problems, single failure surfaces have been considered to reproduce approximately the material strength [20-21]. On the other hand, the conventional formulations for isotropic quasibrittle materials [22] have been extended [23] to describe the orthotropic behaviour, with a material admissible field bounded by a Hill-type yield criterion for compression and a Rankine-type yield criterion for tension, according to different failure mechanisms, i.e. cracking and crushing.

The inclusion of the orthotropic behaviour in the non-linear range causes intrinsic complexities to the macro-model formulation. In the framework of Plasticity, the model

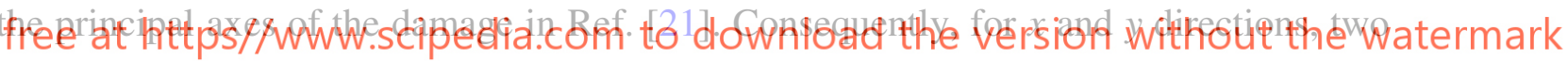
independent damage parameters are assumed, one for compression and one for tension. Their evolution is described by functions similar to those used for isotropic damage of concrete.

Aiming at more accurate but still efficient macro-modelling approaches, this paper presents an implicit orthotropic model based on the classical CDM models. The orthotropic behaviour is simulated by means of an original methodology, which establishes a conveniently defined mathematical relationship between the anisotropic real space and an auxiliary mapped one. In this way, it is possible to solve the problem in the mapped space and to return the results to the real field, with considerable benefits in terms of simplicity and computational efficiency.

The paper is organized as follows: first, the mapping theory at the basis of the proposed orthotropic CDM model is described; then, the implementation of the algorithm into the framework of standard nonlinear finite element programs is detailed; finally, the model 
performance is demonstrated by means of the comparison between experimental and numerical results, with respect to orthotropic failure domains and a shear-wall testing.

\section{Orthotropic Damage Model}

This section presents the formulation of a model based on CDM for the finite element analysis of masonry structures. The orthotropic behaviour of the material is simulated using the concept of mapped stress tensor, firstly introduced in [24] and refined in [2526] afterwards. The method consists in studying the behaviour of a real anisotropic solid by solving the problem in an auxiliary space. The two spaces are related by means of a linear transformation, defined by a symmetric and rank-four transformation tensor, which allows a one-to-one mapping of an image of the stress (or strain) tensor defined in one space into the other and vice versa. In this way, the different behaviour along each material axis can be reproduced by means of a very simple formulation, taking advantage of the well-known isotropic damage models and criteria, while all the information concerning the orthotropy of the material is included in the transformation

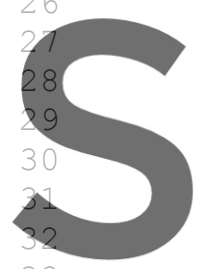

tensor.<smiles>C1CC2CC(C1)C1CC2C1</smiles>

\section{1}

Space Transfo
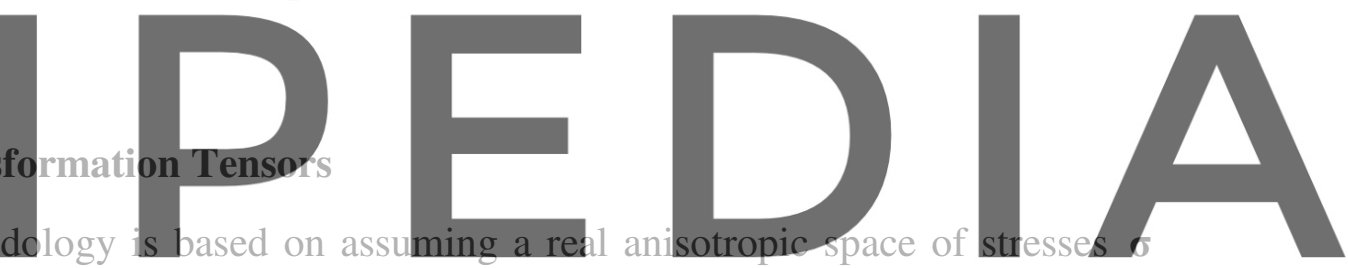

The present methad

and a conjugate space of strains $\mathbb{E}$, such that each of these spaces has, its respective Register fo

free at https//www.scipedia.com to download the version without the watermark image in a mapped space of stresses $\sigma^{*}$ and strains $\varepsilon^{*}$, respectively (see Figure 1 ). The relationship between these spaces is defined by

$$
\begin{aligned}
& \boldsymbol{\sigma}^{*}=\mathbf{A}^{\sigma}: \boldsymbol{\sigma} \\
& \boldsymbol{\varepsilon}^{*}=\mathbf{A}^{\varepsilon}: \boldsymbol{\varepsilon}
\end{aligned}
$$

Where $\mathbf{A}^{\sigma}$ and $\mathbf{A}^{\varepsilon}$ are the transformation tensors, for stresses and strains, respectively, relating the mapped space and the real one. These rank four-tensors embody the natural anisotropic properties of the material.

In order to account for different material behaviour in tension and compression, a split of the stress tensor into tensile and compressive components is introduced, according to [27-33]:

$\boldsymbol{\sigma}^{+}=\sum_{i=1}^{3}\left\langle\sigma_{i}\right\rangle \mathbf{p}_{i} \otimes \mathbf{p}_{i}$

$\boldsymbol{\sigma}^{-}=\boldsymbol{\sigma}-\boldsymbol{\sigma}^{+}$ 
where $\sigma_{i}$ denotes the $i$-th principal stress value from tensor $\boldsymbol{\sigma}$ and $\mathbf{p}_{i}$ represents the unit vector associated with its respective principal direction. The ramp function indicated by the Macaulay brackets $\langle\cdot\rangle$ returns the value of the enclosed expression if positive, but sets a zero value if negative. The split shown by equations (3) and (4) can be expressed in an alternative compact form as follows

$\boldsymbol{\sigma}^{+}=\mathbf{P}: \boldsymbol{\sigma}$

$\boldsymbol{\sigma}^{-}=(\mathbf{I}-\mathbf{P}): \boldsymbol{\sigma}$

where $\mathbf{I}$ is the rank-four identity tensor and $\mathbf{P}$ is a projection operator such that

$\mathbb{P}=\sum_{i=1}^{3} H\left(\sigma_{i}\right) \mathbf{p}_{i} \otimes \mathbf{p}_{i} \otimes \mathbf{p}_{i} \otimes \mathbf{p}_{i}$

where $H\left(\sigma_{i}\right)$ denotes the Heaviside function computed for the $i$-th principal stress $\sigma_{i}$.

The following transformations of the tensile and compressive stress components from
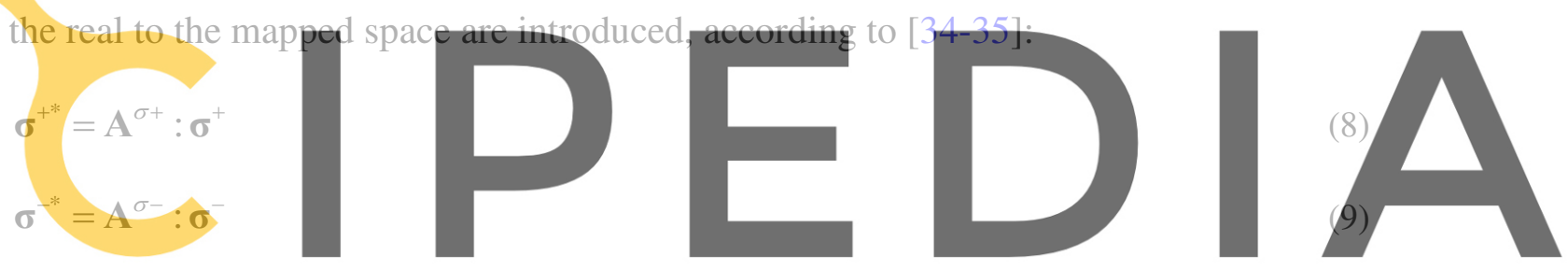

Where $\mathbf{A}^{\sigma+}$ and $\mathbf{A}^{\sigma-}$ are the stress transformation tensors, for positive and negative Register for free at https//Www.scipedia.com to download the version without the watermark components $\sigma^{+}$and $\sigma^{-}$, respectively, relating the mapped and real spaces. Such tensors

are non-singular and positive-definite. The assumption of two distinct stress transformation tensors permits to map the real stresses into the auxiliary space and solve the problem there, by adopting two different isotropic damage criteria for tension and compression.

The stress transformations (8) and (9), making reference to the (local) material coordinate system (denoted by axes 1 and 2, see Figure 2), can be expressed in Voigt's notation as follows:

$$
\left\{\boldsymbol{\sigma}^{ \pm *}\right\}^{\prime}=\left[\mathbf{A}^{\boldsymbol{\sigma}}\right]^{\prime}\left\{\boldsymbol{\sigma}^{ \pm}\right\}^{\prime},\left\{\begin{array}{l}
\sigma_{11}^{ \pm *} \\
\sigma_{22}^{ \pm *} \\
\tau_{12}^{ \pm *}
\end{array}\right\}=\left[\begin{array}{ccc}
\frac{f_{11}^{ \pm *}}{f_{11}^{ \pm}} & 0 & 0 \\
0 & \frac{f_{22}^{ \pm *}}{f_{22}^{ \pm}} & 0 \\
0 & 0 & \frac{f_{12}^{ \pm *}}{f_{12}^{ \pm}}
\end{array}\right]\left\{\begin{array}{c}
\sigma_{11}^{ \pm} \\
\sigma_{22}^{ \pm} \\
\tau_{12}^{ \pm}
\end{array}\right\}
$$


Such mapping transformations are related to in-plane stress conditions, even if the approach can be easily extended to the three dimensional case [26]. Note that from Eq. (10) on apex (') denotes tensors referred to the material coordinate system.

The parameters $f_{i j}^{ \pm^{*}}$ represent the intersections of the mapped failure surfaces with axes 1, 2 and 3. Since two distinct isotropic criteria are assumed in the mapped space, it results that $f_{11}^{+^{*}}=f_{22}^{+^{*}}=f^{+^{*}}$ and $f_{11}^{-*}=f_{22}^{-*}=f^{-^{*}}$. The choice of $f^{+^{*}}$ and $f^{-^{*}}$ is arbitrary. Parameters $f_{12}^{+*}$ and $f_{12}^{-*}$ derive from the particular isotropic criteria adopted for tension and compression. The parameters $f_{i j}^{ \pm}$represent the intersections with axes 1 , 2 and 3 of the real orthotropic failure surfaces.

Making $r_{i j}=\cos \left(x_{i}^{\prime}, x_{j}\right)$, where $x_{i}$ and $x_{i}^{\prime}$ denote the global and local coordinates, the relationship between $\mathbf{A}^{\sigma \pm}$ and $\left(\mathbf{A}^{\sigma \pm}\right)^{\prime}$ is defined as follows

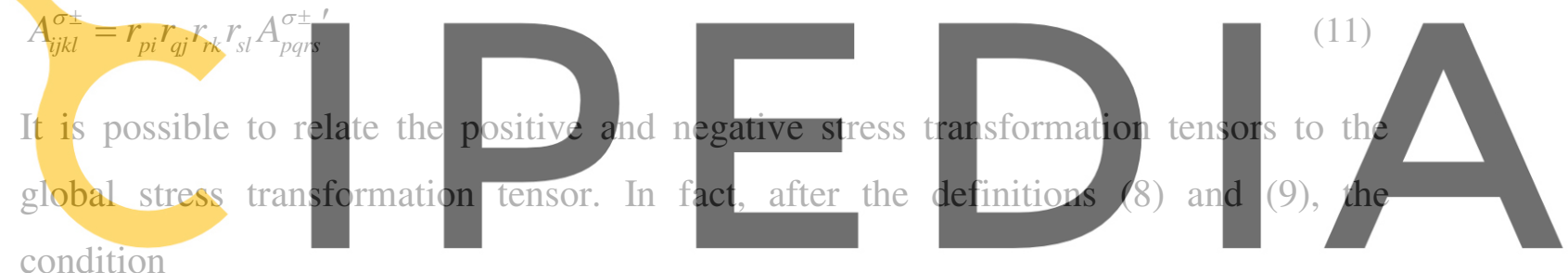
condition

Register for free at https//www.scipedia.com to download the version without the watermark

must still apply. Therefore, the previous expression yieids

$$
\begin{aligned}
& \mathbf{A}^{\sigma}: \boldsymbol{\sigma}=\mathbf{A}^{\sigma+}: \boldsymbol{\sigma}^{+}+\mathbf{A}^{\sigma-}: \boldsymbol{\sigma}^{-} \\
& \mathbf{A}^{\sigma}: \boldsymbol{\sigma}=\mathbf{A}^{\sigma+}: \mathbf{P}: \boldsymbol{\sigma}+\mathbf{A}^{\sigma-}:(\mathbf{I}-\mathbf{P}): \boldsymbol{\sigma}
\end{aligned}
$$

and hence

$$
\mathbf{A}^{\sigma}=\mathbf{A}^{\sigma+}: \mathbf{P}+\mathbf{A}^{\sigma-}:(\mathbf{I}-\mathbf{P})
$$

The strain space transformation tensor $\mathbf{A}^{\varepsilon}$ results after simple calculations:

$$
\mathbf{A}^{\varepsilon}=\left(\mathbf{C}^{*}\right)^{-1}: \mathbf{A}^{\sigma}: \mathbf{C}
$$

where $\mathbf{C}$ and $\mathbf{C}^{*}$ are the (fourth-order) linear constitutive tensors in the real and mapped space, respectively. The former is expressed in the global reference system as follows:

$$
C_{i j k l}=r_{p i} r_{q j} r_{r k} r_{s l} C_{p q r s}^{\prime}
$$




\subsection{Underlying Damage Model and Damage Criteria}

$\sigma^{*}=\left(1-d^{+}\right) \overline{\boldsymbol{\sigma}}^{+*}+\left(1-d^{-}\right) \overline{\boldsymbol{\sigma}}^{-*}$

\section{where the damage indexes $d^{+}$and $d^{-}$are internal variables, each related with the sign}

of the stress and thus with tension and compression.

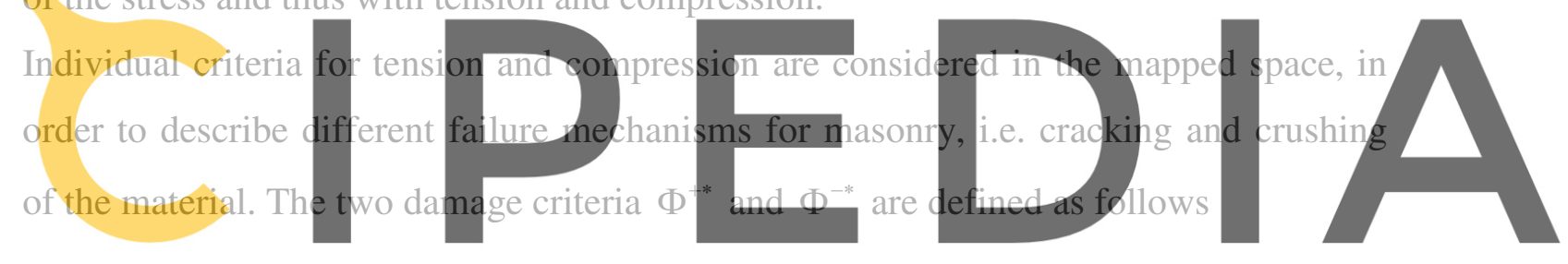

$34 \Phi^{+*}\left(\tau^{+*}, r^{+*}\right)=\tau^{+*}-r^{+*} \leq 0$ (19)

Register for free at' https//www.scipedia.com to download the version without the watermark

Scalar norms $\tau^{ \pm *}$ are postulated in order to identify loading, unloading or reloading situations:

$$
\begin{aligned}
& \tau^{+*}=\left\langle\bar{\sigma}_{1}^{*}\right\rangle \\
& \tau^{-*}=\sqrt{3}\left(K \bar{\sigma}_{o c t}^{-*}+\bar{\tau}_{o c t}^{-*}\right)
\end{aligned}
$$

The former expression represents a tensile Rankine criterion, being $\bar{\sigma}_{1}^{*}$ is the largest principal effective stress. The latter equation is the compressive criterion proposed in [31], which is directly inspired on the Drucker-Prager criterion. Symbols $\bar{\sigma}_{\text {oct }}^{-*}$ and $\bar{\tau}_{\text {oct }}^{-*}$ are the octahedral normal stress and the octahedral shear stress obtained from $\bar{\sigma}^{-*}$, while constant $K$ controls the aperture of the inherent Drucker-Prager cone. 
Variables $r^{+*}$ and $r^{-*}$ in equations (19) and (20) are the internal stress-like variables representing the current damage thresholds in tension and compression. Their values control the size of each (monotonically) expanding damage surface. The expansion of the damage bounding surfaces for loading, unloading and reloading conditions is related to the evolution law of the internal variable, explicitly defined in the following way:

$$
r^{ \pm *}=\max \left[r_{0}^{ \pm *}, \max \left(\tau^{ \pm *}\right)\right]
$$

where the initial values of the tensile and compressive damage thresholds are

$$
r_{0}^{+*}=f^{+*}
$$

$$
r_{0}^{-*}=\frac{\sqrt{3}}{3}(K-\sqrt{2}) f^{-*}
$$

Note that Eq. (24) allows one to compute the current values for $r^{ \pm *}$ in terms of the current values of $\tau^{+*}$ and $\tau^{-*}$, which depend explicitly on the current total strains, see Equations (17), (21) and (22)

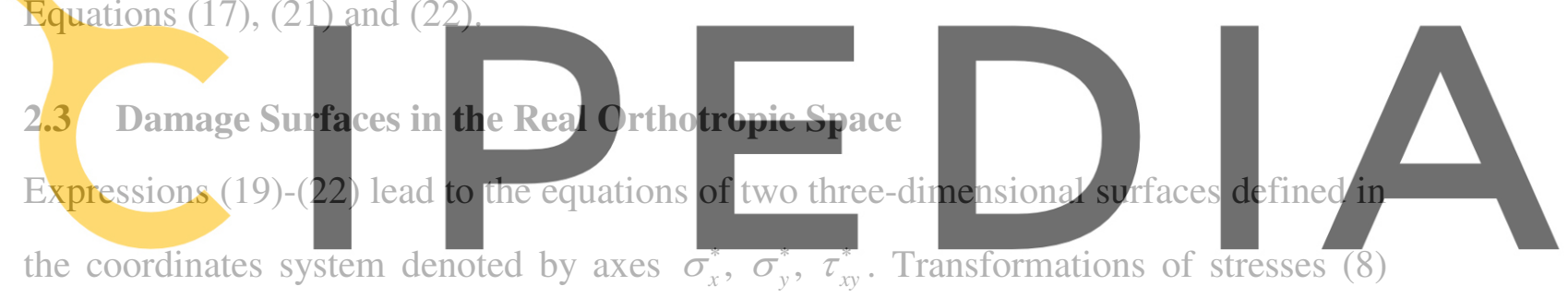

the coordinates system denoted by axes $\sigma_{x}^{*}, \sigma_{v}^{*}, \tau_{x y}^{*}$. Transformations of stresses (8)

mapped space. By means of such a mapping operation, the desired real orthotropic criteria are reproduced in the coordinate system denoted by axes $\sigma_{x}, \sigma_{y}, \tau_{x y}$. Owing to the choices of the Rankine and Faria isotropic criteria in the mapped space, the stress transformation tensors (10) take the diagonal forms in Voigt's notation

$$
\left[\mathbf{A}^{\sigma+}\right]^{\prime}=\left[\begin{array}{ccc}
\frac{f^{+*}}{f_{11}^{+}} & 0 & 0 \\
0 & \frac{f^{+*}}{f_{22}^{+}} & 0 \\
0 & 0 & \frac{f^{+*}}{f_{12}^{+}}
\end{array}\right]
$$




$$
\left[\mathbf{A}^{\sigma-}\right]^{\prime}=\left[\begin{array}{ccc}
\frac{f^{-*}}{f_{11}^{-}} & 0 & 0 \\
0 & \frac{f^{-*}}{f_{22}^{-}} & 0 \\
0 & 0 & \frac{f^{-*}(\sqrt{2}-K) / \sqrt{6}}{f_{12}^{-}}
\end{array}\right]
$$

The choice of $f^{+^{*}}$ and $f^{-*}$ is arbitrary. It is advisable to assume $f^{+^{*}}=f_{11}^{+}$and $f^{-^{*}}=f_{11}^{-}$, in order to obtain $\left(\mathbf{A}_{11}^{\sigma+}\right)^{\prime}=\left(\mathbf{A}_{11}^{\sigma-}\right)^{\prime}=1$. The transformation of space is feasible only if the six parameters $f_{11}^{+}, f_{11}^{-}, f_{22}^{+}, f_{22}^{-}, f_{12}^{+}, f_{12}^{-}$, i.e. the strengths of the real orthotropic material, are known. Such parameters also represent the intersections of the real damage threshold surfaces with axes 1, 2 and 3, see Figure 3. The first group of four strength parameters $\left(f_{11}^{+}, f_{11}^{-}, f_{22}^{+}, f_{22}^{-}\right)$can be estimated by means of uniaxial experimental tests. If such tests are performed under displacement control conditions, it is possible to obtain also the inelastic parmeters that define the model, viz. the four
independent fracture energies. The parameters $f_{12}^{+}$and $f_{12}^{-}$can be derived by the
experimental tests proposed in [10], which weight the shear stress contribution to tensile
and compressive failure. Finally, a biaxial compressive test is required in order to assess

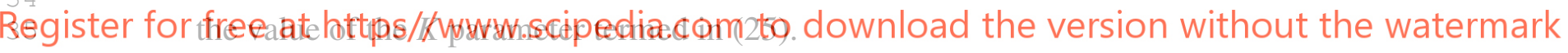

\subsection{Evolution Laws for Damage Variables}

The damage indexes $d^{ \pm}$reported in (18) are monotonically increasing functions such that $0 \leq d^{ \pm}\left(r^{ \pm *}\right) \leq 1$. They are equal to zero when the material is undamaged and equal to one when it is completely damaged. In strict dependence to the definitions given in Section 2.2 for the thresholds $r^{ \pm *}$, appropriate evolution laws are considered for the damage variables $d^{ \pm}$to reproduce both the tensile softening and the compressive hardening/softening observable in masonry. In this work, we assume in the mapped space the detailed expressions given in [29-30] that will not be reiterated here. The postpeak behaviour is defined by means of the fracture energies $G_{f}^{ \pm *}$, normalized with respect to the finite element characteristic length, in order to ensure the FEM solution mesh-independency [37-38]. For further details the reader is referred to the cited references and to the validation example of Section 4.1. 


\section{Numerical Implementation of the Proposed Model}

The steps for implementing the orthotropic damage model into the framework of standard nonlinear finite element programs are given in Table 1.

The proposed model adopts a strain-driven formalism consistent with standard displacement-based finite element codes. This feature provides high algorithmic efficiency, which is of primary importance when practice-oriented analyses are carried out.

\section{Validation Examples}

The first example discusses the nonlinear behaviour in tension and compression of the proposed model. Then, the experimental failure domains found in literature for different types of orthotropic masonry are reproduced numerically. Finally, the structural application to a shear-wall is presented.

Calculations are performed with an enhanced version of the finite element program
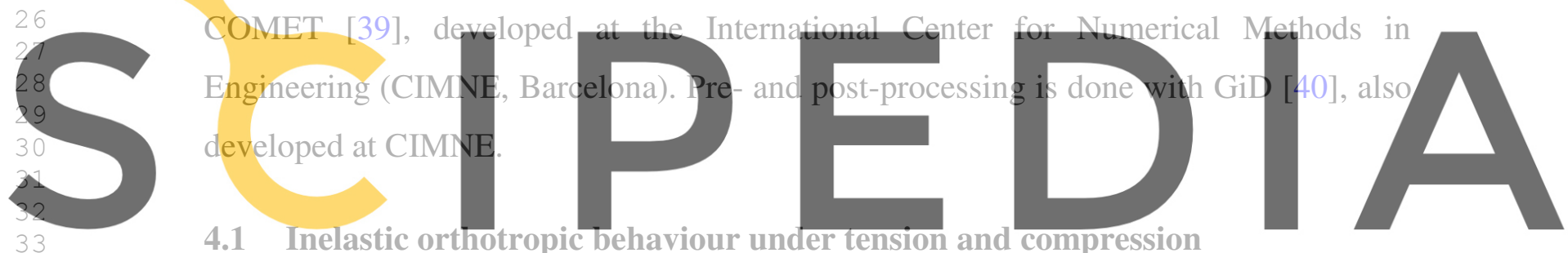

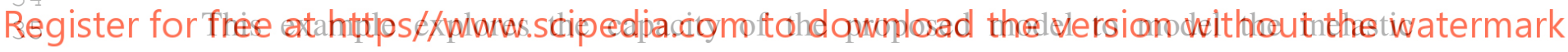
orthotropic behaviour of masonry.

For this purpose, a masonry element subjected to uniaxial tension is considered. The material properties, referred to the material axes 1 and 2, are listed in Table 2. The values chosen for the material parameters illustrate the fact that completely different behaviours along the two material axes can be reproduced.

Figure 4 a shows the stress-strain responses for angles of orthotropy equal to $0^{\circ}, 45^{\circ}$ and $90^{\circ}$. The present model considers an exponential softening law, which is convenient for a quasi-brittle material such as masonry. Once the fracture energy is exhausted, a nontension material is recovered.

As a second step, a masonry specimen subjected to uniaxial compression is considered. The same observations made for the tension test hold. The only exception concerns the compressive nonlinear behaviour. A parabolic hardening followed by exponential softening is considered for the stress-strain diagrams, according to the assumed compressive fracture energy, see Figure $4 \mathrm{~b}$. The peak strength value is assumed to be 
reached simultaneously on both materials axes, i.e. isotropic hardening, followed by orthotropic softening as determined by the different fracture energies. The model allows one to set an ultimate value of the strain, from which the material begins to soften.

As a third step, the behaviour of the proposed model under unloading/reloading conditions is studied. In compliance with the CDM classical theory, in case of unloading the damage does not rise and, consequently, unloading occurs until the origin according to a damaged Young modulus. The damage constitutive law differs from the plasticity constitutive law in that no plastic irreversible deformation occurs: all the deformation is recovered during the unloading, so that the unloading paths are not parallel.

In addition, the two-parameter damage model is able to capture the unilateral behaviour exhibited by the material when passing from tension to compression [27-33]. This is due to the assumption of the stress split to the definition of two different variables to describe tensile and compressive damage, see Equation (18). This peculiarity of the model is emphasized in Figure 4c, which shows the numerical response of a masonry specimen subjected to tensile-compressive cycles. A cyclical displacement history is applied to the specimen with horizontal bed joints. As can be seen from Figure 4c, the unloading occurs until the origin of the stress-strain diagram, according to a damaged stiffness. A successive reloading follows the same unloading branch, until the damage threshold is reached again. When reversing the sign of the external loading, the constitutive model is able to distinguish tension from compression. In particular, the stiffness recovery upon loading reversal is correctly represented. For instance, when passing from tension to compression, the model accounts for the crack closure phenomenon in masonry.

Concerning the representation of irreversible deformation upon unloading, which is not considered in the model at this stage, it is worth mentioning the CDM models of Refs. [31-32] that include inelastic strains in problems with reversal loading.

\subsection{Comparison with Experimental Data of Masonry Strength}

The capability of the proposed model to reproduce the strength of different masonry types is shown next. A comparison with different available experimental data is carried out.

Firstly, the biaxial tests conducted by Page [16-17] on solid clay brick masonry are considered. The tests were conducted for five different orientations, $0^{\circ}, 22.5^{\circ}, 45^{\circ}$, $67.5^{\circ}$ and $90^{\circ}$, of the principal stress with respect to the direction of the mortar beds, in 
order to assess the directional strength characteristics of masonry panels subjected to inplane monotonic loading.

The values assumed for real orthotropic strengths are $f_{11}^{+}=0.43 \mathrm{MPa}, f_{22}^{+}=0.32 \mathrm{MPa}$ and $f_{12}^{+}=0.33 \mathrm{MPa}$ for tension and $f_{11}^{-}=8.74 \mathrm{MPa}, f_{22}^{-}=8.03 \mathrm{MPa}$ and $f_{12}^{-}=2.71 \mathrm{MPa}$ for compression. The parameter $K$ of Equation (25) has been considered equal to 0.118. All the aforementioned values have been selected according to data given by Page [17] and parameters calibrated in Ref. [10]. The composite damage criterion features a low degree of anisotropy $\left(f_{x}^{+} / f_{y}^{+}=1.34\right.$ and $\left.f_{x}^{-} / f_{y}^{-}=1.09\right)$, as shown in Figure 5. For all the tests, the material properties in the 1-axis have been selected for the mapped isotropic behaviour. The comparisons between the experimental values and the model ones are given in Figures $6 \mathrm{a}-\mathrm{c}$, corresponding to orientations of the bed joints equal to $0^{\circ}, 22.5^{\circ}$ and $45^{\circ}$, respectively.

Globally, good agreement is found. The results obtained by the proposed model are also consistent with the simulations obtained with the plasticity model of Lourenco et al. [23]. The Two-Parameters Damage Model benefits from more large efficiency, thanks to its intrinsic simplicity. Moreover, the favourable strain-driven format provides robustness and high algorithmic efficiency, avoiding the problem of possible illconditioning of the return-mapping algorithm in stress-driven orthotropic plasticity models [41].

Secondly, the biaxial tests conducted by Ganz and Thürlimann [42] on hollow clay brick masonry are considered. The values assumed for real orthotropic strengths are $f_{11}^{+}=0.28 \mathrm{MPa}, f_{22}^{+}=0.01 \mathrm{MPa}$ and $f_{12}^{+}=0.04 \mathrm{MPa}$ for tension and $f_{11}^{-}=1.83 \mathrm{MPa}$, $f_{22}^{-}=7.63 \mathrm{MPa}$ and $f_{12}^{-}=3.41 \mathrm{MPa}$ for compression. The parameter $K$ of Equation (25) has been considered equal to 0.072. All the aforementioned values have been selected according to data given by Ganz and Thürlimann [42] and parameters calibrated in Ref. [10]. The composite damage criterion features a high degree of anisotropy $\left(f_{x}^{+} / f_{y}^{+}=28\right.$ and $\left.f_{y}^{-} / f_{x}^{-}=4.17\right)$. These high ratios are due to the high perforation of the clay bricks. For all the tests, the material properties in the 1-axis have been selected for the mapped isotropic behaviour. Figure 7 shows the shape of the adopted composite damage criterion both with the points representing the set of strength experimental data. It appears that the tension regime represents the majority of the composite damage surface domain. 
The test results, the proposed model results and the ratio between experimental and predicted failure are given in Table 3. Notice that this ratio is a measure of the norm of the stress vector in the $\left(\sigma_{x}, \sigma_{y}, \tau_{x y}\right)$-space which equals $\left(\sigma_{x}^{2}+\sigma_{y}^{2}+\tau_{x y}^{2}\right)^{1 / 2}$. Panels K5 and $\mathrm{K} 9$ are not included because the boundary conditions affected the failure mode of panel K5 and panel K9 included reinforcement.

The model seems to be able to reproduce the strength behaviour of this type of anisotropic masonry with good accuracy. The error is bounded by a maximum value of $5 \%$, corresponding to test $\mathrm{K} 8$. The mean of the ratios is equal to 0.995 .

Finally, the biaxial tests conducted by Lurati et al. [43] on hollow concrete block masonry are considered. The values assumed for real strengths are $f_{11}^{+}=0.01 \mathrm{MPa}$, $f_{22}^{+}=0.01 \mathrm{MPa}$ and $f_{12}^{+}=0.01 \mathrm{MPa}$ for tension and $f_{11}^{-}=5.78 \mathrm{MPa}, f_{22}^{-}=9.12 \mathrm{MPa}$ and $f_{12}^{-}=3.98 \mathrm{MPa}$ for compression. This type of masonry is practically a no-tension material. The parameter $K$ of Equation (25) has been considered equal to 0.0. All the aforementioned values have been selected according to data given by Lurati et al. [43] and parameters calibrated in Ref. [10]. The composite damage criterion features a reasonable degree of anisotropy in compression, with $f_{y}^{-} / f_{x}^{-}=1.58$. For all the tests, the material properties in the 1-axis have been selected for the mapped isotropic behaviour. Figure 8 shows the shape of the adopted composite damage criterion both with the points representing the set of strength experimental data.

The comparison between experimental and numerical results is reported in Table 4 . Panel ZSW3 is not considered because the head joints were not filled. The model has shown its ability to simulate the strength behaviour of this type of anisotropic masonry with good accuracy. The error is bounded by a maximum value of $7 \%$, corresponding to test ZSW7. The mean of the ratios is equal to 0.993 .

\subsection{TU Eindhoven Shear-Walls}

The shear walls J2G and J3G with a central opening tested at TU Eindhoven [44] are here considered. They have dimensions of $990 \times 1000 \mathrm{~mm}^{2}$ and are constituted by 18 courses, of which 16 courses are active and 2 courses are clamped in steel beams. The walls are made of wire-cut solid clay bricks with dimensions $210 \times 52 \times 100 \mathrm{~mm}^{3}$ and 10 $\mathrm{mm}$ thick mortar, prepared with a volumetric cement:lime:sand ratio of 1:2:9. Vertical precompression uniformly distributed forces $\mathrm{p}=0.30 \mathrm{~N} / \mathrm{mm}^{2}$ are applied to the walls, before a horizontal load is monotonically increased under top displacement control in a 
confined way, i.e. keeping the bottom and top boundaries horizontal and precluding any vertical movement.

For the numerical analysis, the wall is represented by 5982 bi-dimensional plane-stress 3-noded linear triangular elements. The computational domain is discretized with an unstructured mesh with average mesh size of $h_{e}=20 \mathrm{~mm}$ (3128 nodes). The discrete problem is solved incrementally, in a (pseudo) time step-by-step manner. The analysis is completed by means of 500 equal time steps. Within each step, a modified NewtonRaphson method (using the secant stiffness matrix), together with a line search procedure, is used to solve the corresponding non-linear system of equations. Convergence at a particular time step is attained when the ratio between the norm of the iterative residual forces and the norm of the total external forces is lower than $1 \%$.

The values of the mechanical parameters used in the numerical analysis to describe the masonry behaviour are summarized in Table 5. Some of them are the mechanical characteristics of masonry provided in [44], others are data obtained via a homogenization procedure [45].

Figure 9a shows iso-contours for the tensile damage, which arises from the opening and propagates towards the top and the bottom of the wall. In addition, tensile damage arises from the vertical external sides of the wall, involving the top left pier next to the opening and the bottom right one. Such approximate representation of the tensile damage as a smeared phenomenon can be considerably improved resorting to the cracktracking technique proposed in Ref. [9], which forces the tensile damage to develop along a single row of finite elements. In this way, the tensile damage is represented in the form of localized cracks, similar to the ones typically observed on masonry structures. Figure $9 \mathrm{~b}$ shows the discrete tensile cracks predicted by the proposed model combined with the aforementioned crack-tracking algorithm. Compared with the smeared approach, the localized one shows a better capacity to predict the real collapsing mechanism. Figure $9 \mathrm{c}$ depicts the compressive smeared damage contour. As shown, the model predicts correctly the location of the areas affected by material compressive failure. The failure mechanism is properly represented, with the compressed struts located next to the opening which fail at both of their ends. Figure $9 \mathrm{~d}$ shows the computed deformed shape corresponding to an imposed horizontal displacement of $20 \mathrm{~mm}$, with a displacement amplification factor of 30 .

The comparison between the calculated and experimental load-displacement diagrams is shown in Figure 10. Although both walls $\mathrm{J} 2 \mathrm{G}$ and $\mathrm{J} 3 \mathrm{G}$ were tested under the same 
conditions, the latter one resisted a lower ultimate loading. The numerical results agree reasonably with wall $\mathrm{J} 2 \mathrm{G}$, as also found in other studies $[5,46]$.

Finally, Figures 11a-b show the comparison between the result obtained in [5] with a micro-model including the distinct representation of constituents and the visualization of the maximum principal strain vectors both with the compressive damage iso-contours derived from the proposed model. The concentration of the displacement gradients (strains) in the elements lying along the computed crack is evident. Therefore, the resolution of the cracks is optimal for the mesh used.

\section{Conclusions}

In the present paper, an original method is proposed for the finite element analysis of masonry structures. This working strategy, based on CDM and on the concept of space mapping, allows the establishment of an implicit orthotropic damage criterion in the real anisotropic space by using the damage criterion formulated in an auxiliary mapped space, with all the advantages implied by this. The model is able to capture the stiffness, the strength and the inelastic dissipation in each material direction. The implementation of this theory in finite element codes is straightforward. The procedure can be applied to the analysis of masonry structures, such as horizontally and vertically in-plane loaded masonry walls.

\section{Acknowledgments}

The studies presented here have been developed within the research projects BIA200604127 and SEDUREC (CSD2006-00060), funded by DGE of the Spanish Ministry of Science and Technology, whose assistance is gratefully acknowledged. The authors thank Prof. Sergio Oller for his helpful suggestions. 


\section{References}

[1] Roca P, Cervera M, Gariup G, Pelà L. Structural Analysis of Masonry Historical Constructions. Classical and Advanced Approaches. Arch Comput Methods Eng 2010;17:299-325.

[2] Roca P, Molins C, Marí AR. Strength capacity of masonry wall structures by the equivalent frame method. J Struct Eng 2005;131(10):1601-1610.

[3] Brencich A, Lagomarsino S. A macro-element dynamic model for masonry shear walls. In: Pande GN and Middleton J, editors. Computer methods in structural masonry - 4, Proc of the Int Symp, E\&FN Spon, London; 1998.

[4] Lofti HR, Shing PB. Interface model applied to fracture of masonry structures. J Struct Eng 1994;120(1):63-80.

[5] Lourenço PB, Rots JG. Multi-surface interface model for the analysis of masonry structures. J Eng Mech 1997;123(7):660-668.

[6] Pelà L, Aprile A, Benedetti A. Seismic assessment of masonry arch bridges. Eng Struct 2009;31(8):1777-1788.

[7] Mallardo V, Malvezzi R, Milani E, Milani G. Seismic vulnerability of historical masonry buildings: A case study in Ferrara. Eng Struct 2008;30:2223-2241.

[8] Martínez G, Roca P, Caselles O, Clapés J. Characterization of the Dynamic Response for the Structure of Mallorca Cathedral. In: Lourenço PB, Roca P, Modena C, Agrawal S, editors. Structural Analysis of Historical Constructions, New Delhi; 2006.

[9] Cervera M, Pelà L, Clemente R, Roca P. A crack-tracking technique for localized damage in quasi-brittle materials. Eng Fract Mech 2010;77(13):2431-2450.

[10] Lourenço PB, Rots JG, Blaauwendraad J. Continuum model for masonry: parameter estimation and validation. J Struct Eng 1998;124(6):642-652.

[11] Benedetti A, Pelà L, Aprile A. Masonry properties determination via splitting tests on cores with a rotated mortar layer. In: Sinha B and Tanaçan L, editors. Proceedings of $8^{\text {th }}$ International Seminar on Structural Masonry, Istanbul; 2008.

[12] Lourenço PB, Milani G, Tralli A, Zucchini A. Analysis of masonry structures: review and recent trends of homogenisation techniques. Can J Civ Eng 2007;34:1443-1457.

[13] Sinha B, Hendry AW. Racking tests on storey-height shear-wall structures with openings, subjected to pre-compression. Designing engineering \& construction with masonry products, Gulf Publishing Co., Houston; 1969, p. 192-199. 
[14] Yokel FY, Fattal SG. Failure hypothesis for masonry shear walls. J Struct Div 1976;102(3):515-532.

[15] Hamid AA, Drysdale RG. Proposed failure criteria for concrete block masonry under biaxial stresses. J Struct Eng 1981;107(8):1675-1687.

[16] Page AW. The biaxial compressive strength of brick masonry. Proc Inst Civil Engrs 1981;71(2):893-906.

[17] Page AW. The strength of brick masonry under biaxial tension-compression. Int J Mas Constr 1983;3(1):26-31.

[18] Mann W, Müller H. Failure of Shear-Stressed Masonry-An Enlarged Theory, Tests and Application to Shear Walls. Proc Brit Ceramic Soc 1982;30:223-235.

[19] Dhanasekar M, Page AW, Kleeman PW. The failure of brick masonry under biaxial stresses. Proc Intsn Civ Engrs 1985;79(2):295-313.

[20] Syrmakesis CA, Asteris PG. Masonry Failure Criterion Under Biaxial Stress State. J Mat Civ Eng 2001;13:58-64.

[21] Berto L, Saetta A, Scotta R, Vitaliani R. An orthotropic damage model for masonry structures. Int J Numer Methods Engng 2002;55:127-157.

[22] Feenstra PH, De Borst R. A composite plasticity model for concrete. Int J Solids Struct 1996;33(5):707-730.

[23] Lourenço PB, De Borst R, Rots JG. Plane Stress Softening Plasticity Model For Orthotropic Materials. Int J Numer Methods Engng 1997;40:4033-4057.

[24] Betten J. Applications of tensor functions to the formulation of yield criteria for anisotropic materials. Int J Plast 1988;4:29-46.

[25] Oller S, Botello S, Miquel J, Oñate E. An anisotropic elastoplastic model based on an isotropic formulation. Eng Comput 1995;12(3):245-262.

[26] Oller S, Car E, Lubliner J. Definition of a general implicit orthotropic yield criterion. Comput Methods Appl Mech Engrg 2003;192:895-912.

[27] Cervera M, Oliver J, Faria R. Seismic evaluation of concrete dams via continuum damage models. Earthq Eng Struct D 1995;24(9):1225-1245.

[28] Cervera M, Oliver J, Manzoli O. A Rate-Dependent Isotropic Damage Model for the Seismic Analysis of Concrete Dams. Earthq Eng Struct D 1996;25:987-1010.

[29] Cervera M, Oliver J, Prato T. Thermo-Chemo-Mechanical Model for Concrete. II: Damage and Creep. J Eng Mech 1999;125(9):1028-1039. 
[30] Cervera M. Viscoelasticity and Rate-Dependent Continuum Damage Models. CIMNE, Monograph No-79, Barcelona; 2003.

[31] Faria R, Oliver J, Cervera M. A Strain-Based Plastic Viscous-Damage Model for Massive Concrete Structures. Int J Solids Struct 1998;35(14):1533-1558.

[32] Faria R, Oliver J, Cervera M. On Isotropic Scalar Damage Models For The Numerical Analysis Of Concrete Structures. CIMNE, Monograph PI198, Barcelona; 2000.

[33] Faria R, Oliver J, Cervera M. Modeling Material Failure in Concrete Structures under Cyclic Actions. J Struct Eng 2004;130(12):1997-2005.

[34] Pelà L. Continuum Damage Model for Nonlinear Analysis of Masonry Structures. Ph.D. Thesis. Technical University of Catalonia, University of Ferrara; 2009.

[35] Pelà L, Cervera M, Roca P. Continuum damage model for orthotropic materials: Application to masonry. Comput Methods Appl Mech Engrg 2011;200:917-930.

[36] Lemaitre J, Chaboche JL. Aspects phénoménologiques de la rupture par endommagement. J Méc Appl 1978;2:317-365.

[37] Bazant ZP, Oh BH. Crack band theory for fracture of concrete. Mater Struct 1983;16:155177.

[38] Cervera M, Chiumenti M. Mesh objective tensile cracking via a local continuum damage model and a crack tracking technique. Comput Methods Appl Mech Engng 2006;196:304-20.

[39] Cervera M, Agelet de Saracibar C, Chiumenti M. COMET: COupled MEchanical and Thermal analysis - Data Input Manual Version 5.0. CIMNE, Technical report IT-308, Barcelona; 2002.

[40] http://gid.cimne.upc.es/, website of CIMNE, Technical University of Catalonia, Barcelona, 2002.

[41] Lourenço PB, Rots JG, Feenstra PH. A "tensile" Rankine-type orthotropic model for masonry. In: Pande GN and Middleton J, editors. Computer methods in structural masonry 3, Books \& Journals International, Swansea; 1995.

[42] Ganz HR, Thürlimann B. Tests on the biaxial strength of masonry (in German). Report No. 7502-3, Institute of Structural Engineering, ETH Zurich, 1982.

[43] Lurati F, Graf H, Thürlimann B. Experimental determination of the strength parameters of concrete masonry (in German). Report No. 8401-2, Institute of Structural Engineering, ETH Zurich, 1990.

[44] Raijmakers TMJ, Vermeltfoort ATh. Deformation controlled tests in masonry shear walls (in Dutch). Research report TNO-Bouw, report B-92-1156, Delft, 1992. 
[45] Lourenço PB. Computational strategies for masonry structures. Ph.D. Thesis. Delft University Press; 1996.

[46] Van Zijl GPAG. Modeling masonry shear-compression: role of dilatancy highlighted. J Eng Mech 2004;130(11):1289-1296.

\section{Figures Captions}

Figure 1 Relationship between the real anisotropic space and the mapped isotropic space [26].

Figure 2 Global $(x-y)$ and material (1-2) coordinate systems.

Figure 3 Damage surfaces assumed in the real space and in the mapped space.

Figure 4 Stress-strain responses to uniaxial tension (a) and unixial compression (b) for different angles of orthotropy. Uniaxial response under cyclical displacement history (c).

Figure 5 Calculated damage surface for solid clay brick masonry $\left(\theta=0^{\circ}\right)$, according to experimental tests conducted by Page [16-17].

Figure 6 Comparisons between the proposed model, the model of Lourenço et al. [23] and the experimental results from Page [17]: a) $\theta=0^{\circ}$; b) $\theta=22.5^{\circ}$ and c) $\theta=45^{\circ}$.

Figure 7 Calculated damage surface for hollow clay brick masonry and experimental results obtained by Ganz and Thürlimann [42].

Figure 8 Calculated damage surface for hollow concrete block masonry and experimental results obtained by Lurati et al. [43].

Figure 9 TU Eindhoven Walls [44]: a) smeared damage contour; b) localized damage contour [9]; c) compressive damage contour; d) deformed mesh (x30).

Figure 10 Comparison between experimental and numerical load vs. displacement diagrams for walls $\mathrm{J} 2 \mathrm{G}$ and $\mathrm{J} 3 \mathrm{G}$.

Figure 11 Comparison between numerical results: a) micro-model [5] and b) proposed macro-model. 
Table 1 Algorithm used for the proposed model

\section{START}

- LOAD INCREMENTAL LOOP: $n=1$, NINCR

- EQUILIBRIUM ITERATION LOOP: $i=1$, NITER

IF $(n>1$ or $i>1)$ GOTO 2

1) Define strengths, constitutive tensors and rotation tensors

$$
\begin{aligned}
& f_{11}^{+}, f_{22}^{+}, f_{12}^{+}, f_{11}^{+*}, f_{22}^{+*}, f_{12}^{+*} \\
& f_{11}^{-}, f_{22}^{-}, f_{12}^{-}, f_{11}^{-*}, f_{22}^{-*}, f_{12}^{-*} \\
& \mathbf{C}^{\prime}, \mathbf{C}
\end{aligned}
$$

2) Calculate the transformation tensors:

$$
\left(\mathbf{A}^{\sigma+}\right)^{\prime},\left(\mathbf{A}^{\sigma-}\right)^{\prime}, \mathbf{A}^{\sigma+}, \mathbf{A}^{\sigma+}
$$

3) Compute tangent stiffness:

$$
\begin{aligned}
& { }^{n}\left(\mathbf{K}^{(e)}\right)^{i-1}=\int_{V} \mathbf{B}:{ }^{n}\left(\mathbf{C}^{\mathrm{tan}}\right)^{i-1}: \mathbf{B} d V \\
& { }^{n}(\mathbf{K})^{i-1}=\mathbf{A}_{e=1}^{n e}{ }^{n}\left(\mathbf{K}^{(e)}\right)^{i-1}
\end{aligned}
$$

4) Compute displacement and strains:

$$
\begin{aligned}
& { }^{n}(\delta \mathbf{U})^{i}={ }^{n}\left(\mathbf{K}^{-1}\right)^{i-1} \cdot{ }^{n}\left(\mathbf{F}_{\text {resid }}\right)^{i-1} \\
& { }^{n}(\Delta \mathbf{U})^{i}={ }^{n}(\Delta \mathbf{U})^{i-1}+{ }^{n}(\delta \mathbf{U})^{i} \\
& { }^{n}(\boldsymbol{\varepsilon})^{i}=\mathbf{B}:{ }^{n}(\mathbf{U})^{i}
\end{aligned}
$$

5) Calculate real effective stresses and split:

$$
\begin{aligned}
& { }^{n}(\overline{\boldsymbol{\sigma}})^{i}=\mathbf{C}:{ }^{n}(\boldsymbol{\varepsilon})^{i} \\
& (\mathbf{P})^{i}=\sum_{j=1}^{3} H\left(\bar{\sigma}_{j}\right) \mathbf{p}_{j} \otimes \mathbf{p}_{j} \otimes \mathbf{p}_{j} \otimes \mathbf{p}_{j} \\
& { }^{n}\left(\overline{\boldsymbol{\sigma}}^{+}\right)^{i}=(\mathbf{P})^{i}:{ }^{n}(\overline{\boldsymbol{\sigma}})^{i} \\
& { }^{n}\left(\overline{\boldsymbol{\sigma}}^{-}\right)^{i}={ }^{n}(\overline{\boldsymbol{\sigma}})^{i}-{ }^{n}\left(\overline{\boldsymbol{\sigma}}^{+}\right)^{i}=\left[\mathbf{I}-(\mathbf{P})^{i}\right]:{ }^{n}(\overline{\boldsymbol{\sigma}})^{i}
\end{aligned}
$$

6) Transform real effective stresses to the mapped space:

$$
\begin{gathered}
{ }^{n}\left(\overline{\boldsymbol{\sigma}}^{+^{*}}\right)^{i}=\mathbf{A}^{\sigma+}:{ }^{n}\left(\overline{\boldsymbol{\sigma}}^{+}\right)^{i} \\
{ }^{n}\left(\overline{\boldsymbol{\sigma}}^{-*}\right)^{i}=\mathbf{A}^{\sigma-}:{ }^{n}\left(\overline{\boldsymbol{\sigma}}^{-}\right)^{i}
\end{gathered}
$$


7) Compute damage indexes and total stresses in the mapped space:

$$
\begin{aligned}
& { }^{n}\left(\boldsymbol{\sigma}^{+*}\right)^{i}=\left(1-d^{+}\right)^{n}\left(\overline{\boldsymbol{\sigma}}^{+*}\right)^{i} \\
& { }^{n}\left(\boldsymbol{\sigma}^{-*}\right)^{i}=\left(1-d^{-}\right)^{n}\left(\overline{\boldsymbol{\sigma}}^{-*}\right)^{i}
\end{aligned}
$$

8) Return to the real orthotropic stress space:

$$
\begin{aligned}
& { }^{n}\left(\boldsymbol{\sigma}^{+}\right)^{i}=\left(\mathbf{A}^{\sigma+}\right)^{-1}:{ }^{n}\left(\boldsymbol{\sigma}^{+*}\right)^{i} \\
& { }^{n}\left(\boldsymbol{\sigma}^{-}\right)^{i}=\left(\mathbf{A}^{\sigma-}\right)^{-1}:{ }^{n}\left(\boldsymbol{\sigma}^{-*}\right)^{i} \\
& { }^{n}(\boldsymbol{\sigma})^{i}={ }^{n}\left(\boldsymbol{\sigma}^{+}\right)^{i}+{ }^{n}\left(\boldsymbol{\sigma}^{-}\right)^{i}
\end{aligned}
$$

9) Compute residual forces:

$$
\begin{aligned}
& { }^{n}\left(\mathbf{F}_{\text {resid }}^{(e)}\right)^{i}=\int_{V} \mathbf{B}^{T}:{ }^{n}(\boldsymbol{\sigma})^{i} d V-\mathbf{f}_{\text {ext }} \\
& { }^{n}\left(\mathbf{F}_{\text {resid }}\right)^{i}=\mathbf{A}_{e=1}^{n e}{ }^{n}\left(\mathbf{F}_{\text {resid }}^{(e)}\right)^{i} \\
& \mathrm{IF} \frac{\left\|^{n}\left(\mathbf{F}_{\text {resid }}\right)^{i}\right\|}{\mathbf{f}_{\text {ext }} \|}>\text { tol } \Rightarrow i=i+1 \text { GO BACK TO } 3
\end{aligned}
$$

else:

- END EQUILIBRIUM ITERATION LOOP

Converged solution for the $\mathrm{n}^{\text {th }}$ increment.

Compute new incremental solution: $n=n+1$

- END LOAD INCREMENTAL LOOP 
Table 2 Material properties for uniaxial tension/compression test.

\begin{tabular}{lcllcc}
\hline \multicolumn{5}{c}{ Material Properties } \\
\hline$E_{1}=E^{*}$ & $3000 \mathrm{MPa}$ & ${f_{11}}^{+}=f^{+*}$ & $0.35 \mathrm{MPa}$ & $f_{1}^{-}=f^{-*}$ & $7.00 \mathrm{MPa}$ \\
$E_{2}$ & $2000 \mathrm{MPa}$ & ${f_{22}{ }^{+}}^{-}$ & $0.15 \mathrm{MPa}$ & $f_{2}^{-}$ & $3.00 \mathrm{MPa}$ \\
$v_{12}=v^{*}$ & 0.1 & ${f_{12}{ }^{+}}^{+}$ & $0.20 \mathrm{MPa}$ & $f_{12}{ }^{-}$ & $3.00 \mathrm{MPa}$ \\
$v_{21}$ & 0.15 & ${G_{f, 1}{ }^{+}=G^{+*}} 100 \mathrm{~J} / \mathrm{m}^{2}$ & $G_{f, 1}=G^{-*}$ & $40000 \mathrm{~J} / \mathrm{m} 2$ \\
$G_{12}$ & $900 \mathrm{MPa}$ & ${G_{f, 2}{ }^{+}}$ & $13.8 \mathrm{~J} / \mathrm{m}^{2}$ & $G_{f, 2}{ }^{-}$ & $5510 \mathrm{~J} / \mathrm{m} 2$ \\
\hline
\end{tabular}


Table 3 Comparison between the proposed model and the experimental results obtained by Ganz and Thürlimann [42].

\begin{tabular}{cccccccc}
\hline & \multicolumn{3}{c}{ Experimental results } & \multicolumn{3}{c}{ Present Model } \\
Panel & $\sigma_{x}$ & $\sigma_{y}$ & $\tau_{x y}$ & $\sigma_{x}$ & $\sigma_{y}$ & $\tau_{x y}$ & Ratio \\
& $(\mathrm{MPa})$ & $(\mathrm{MPa})$ & $(\mathrm{MPa})$ & $(\mathrm{MPa})$ & $(\mathrm{MPa})$ & $(\mathrm{MPa})$ & \\
\hline $\mathrm{K} 1$ & -0.08 & -0.92 & 0.42 & -0.08 & -0.92 & 0.44 & 0.99 \\
$\mathrm{~K} 2$ & -0.17 & -1.42 & 0.62 & -0.17 & -1.42 & 0.61 & 1.00 \\
$\mathrm{~K} 3$ & 0.00 & -7.63 & 0.00 & 0.00 & -7.63 & 0.00 & 1.00 \\
$\mathrm{~K} 4$ & -1.83 & 0.00 & 0.00 & -1.83 & 0.00 & 0.00 & 1.00 \\
$\mathrm{~K} 6$ & -0.32 & -0.32 & 0.32 & -0.32 & -0.32 & 0.34 & 0.98 \\
$\mathrm{~K} 7$ & -0.39 & -2.25 & 0.93 & -0.39 & -2.25 & 0.94 & 1.00 \\
$\mathrm{~K} 8$ & -0.22 & -0.04 & 0.09 & -0.22 & -0.04 & 0.12 & 0.95 \\
$\mathrm{~K} 10$ & -2.11 & -6.44 & 0.00 & -2.15 & -6.44 & 0.00 & 1.00 \\
$\mathrm{~K} 11$ & -2.04 & -4.49 & 1.23 & -2.04 & -4.49 & 1.39 & 0.99 \\
$\mathrm{~K} 12$ & -2.03 & -2.03 & 1.08 & -2.03 & -2.03 & 0.69 & 1.04 \\
\hline
\end{tabular}


Table 4 Comparison between the proposed model and the experimental results obtained by Lurati et al. [43].

\begin{tabular}{lccccccc}
\hline & \multicolumn{3}{c}{ Experimental results } & \multicolumn{3}{c}{ Present model } \\
Panel & $\sigma_{x}$ & $\sigma_{y}$ & $\tau_{x y}$ & $\sigma_{x}$ & $\sigma_{y}$ & $\tau_{x y}$ & Ratio \\
& $(\mathrm{MPa})$ & $(\mathrm{MPa})$ & $(\mathrm{MPa})$ & $(\mathrm{MPa})$ & $(\mathrm{MPa})$ & $(\mathrm{MPa})$ & \\
\hline ZSW1 & 0.00 & -9.12 & 0.00 & 0.00 & -9.12 & 0.00 & 1.00 \\
ZSW2 & -6.12 & -0.83 & 0.00 & -6.01 & -0.83 & 0.00 & 1.02 \\
ZSW4 & -5.98 & -9.13 & 0.00 & -5.76 & -9.12 & 0.00 & 1.01 \\
ZSW5 & -3.06 & -3.06 & 3.06 & -3.06 & -3.06 & 3.07 & 1.00 \\
ZSW6 & -4.60 & -4.60 & 2.93 & -4.60 & -4.60 & 3.06 & 0.99 \\
ZSW7 & -6.12 & -6.12 & 0.00 & -6.60 & -6.60 & 0.00 & 0.93 \\
ZSW8 & -2.34 & -0.40 & 0.97 & -2.34 & -0.40 & 0.98 & 1.00 \\
ZSW9 & -0.97 & -5.66 & 2.35 & -0.97 & -5.66 & 2.36 & 1.00 \\
\hline
\end{tabular}


Table 5 Material properties adopted in the numerical analysis of TU Eindhoven Shear Walls [44].

\begin{tabular}{lcllcc}
\hline \multicolumn{5}{c}{ Material Properties } \\
\hline$E_{1}=E^{*}$ & $7520 \mathrm{MPa}$ & $f_{11}{ }^{+}=f^{+*}$ & $0.35 \mathrm{MPa}$ & $f_{1}^{-}=f^{-*}$ & $6.30 \mathrm{MPa}$ \\
$E_{2}$ & $3960 \mathrm{MPa}$ & $f_{22}{ }^{+}$ & $0.25 \mathrm{MPa}$ & $f_{2}^{-}$ & $4.50 \mathrm{MPa}$ \\
$v_{12}=v^{*}$ & 0.09 & ${f_{12}{ }^{+}}^{*}$ & $0.30 \mathrm{MPa}$ & $f_{12}^{-}$ & $3.00 \mathrm{MPa}$ \\
$v_{21}$ & 0.05 & ${G_{f, 1}}^{+}=G^{+*}$ & $50 \mathrm{~J} / \mathrm{m}^{2}$ & $G_{f, 1}^{-}=G^{-*}$ & $20000 \mathrm{~J} / \mathrm{m} 2$ \\
$G_{12}$ & $1460 \mathrm{MPa}$ & ${G_{f, 2}}^{+}$ & $48 \mathrm{~J} / \mathrm{m}^{2}$ & $G_{f, 2}^{-}$ & $19400 \mathrm{~J} / \mathrm{m} 2$ \\
\hline
\end{tabular}


REAL ANISOTROPIC STRESS SPACE
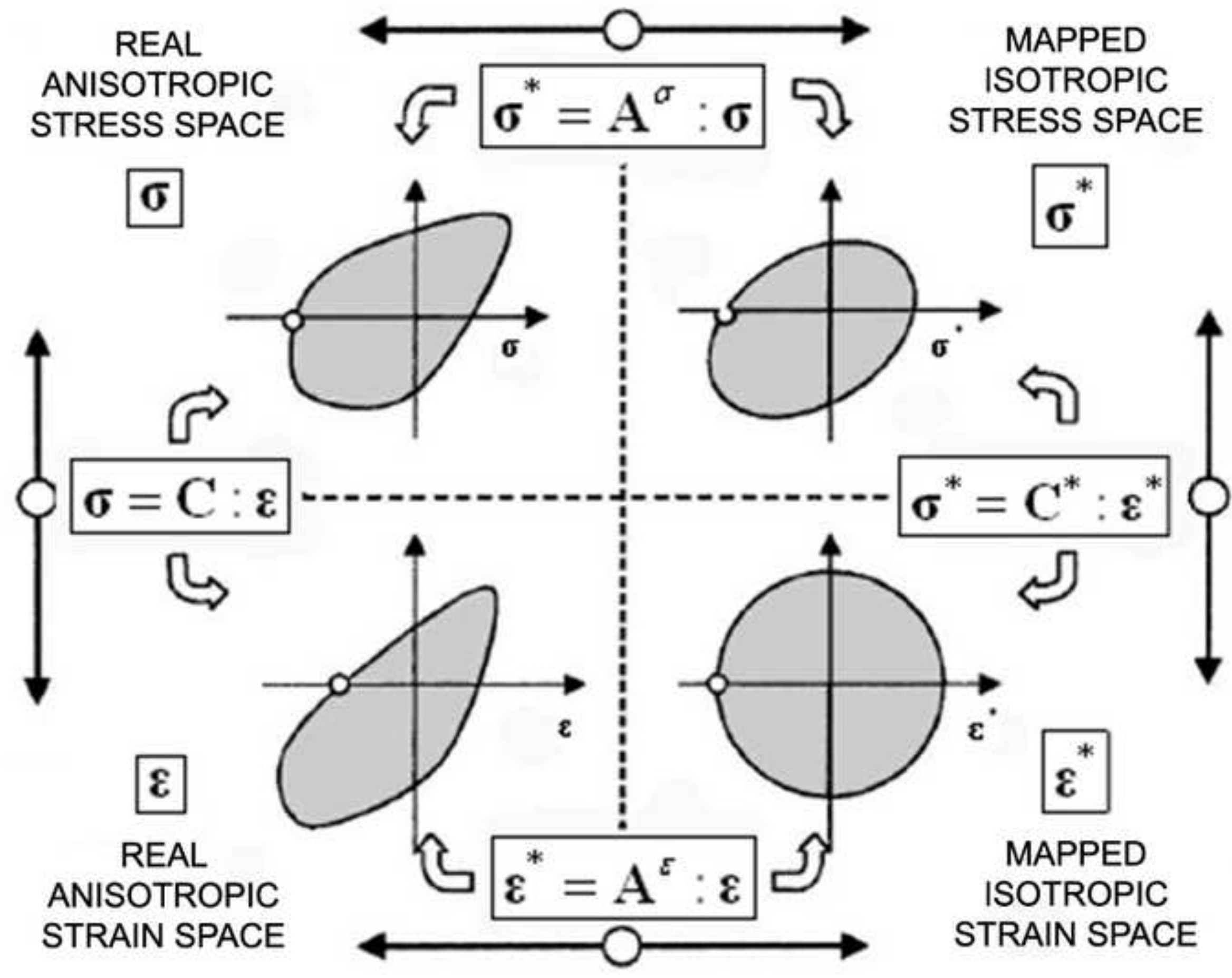

MAPPED ISOTROPIC STRESS SPACE 


\section{Figure 2}

Click here to download high resolution image

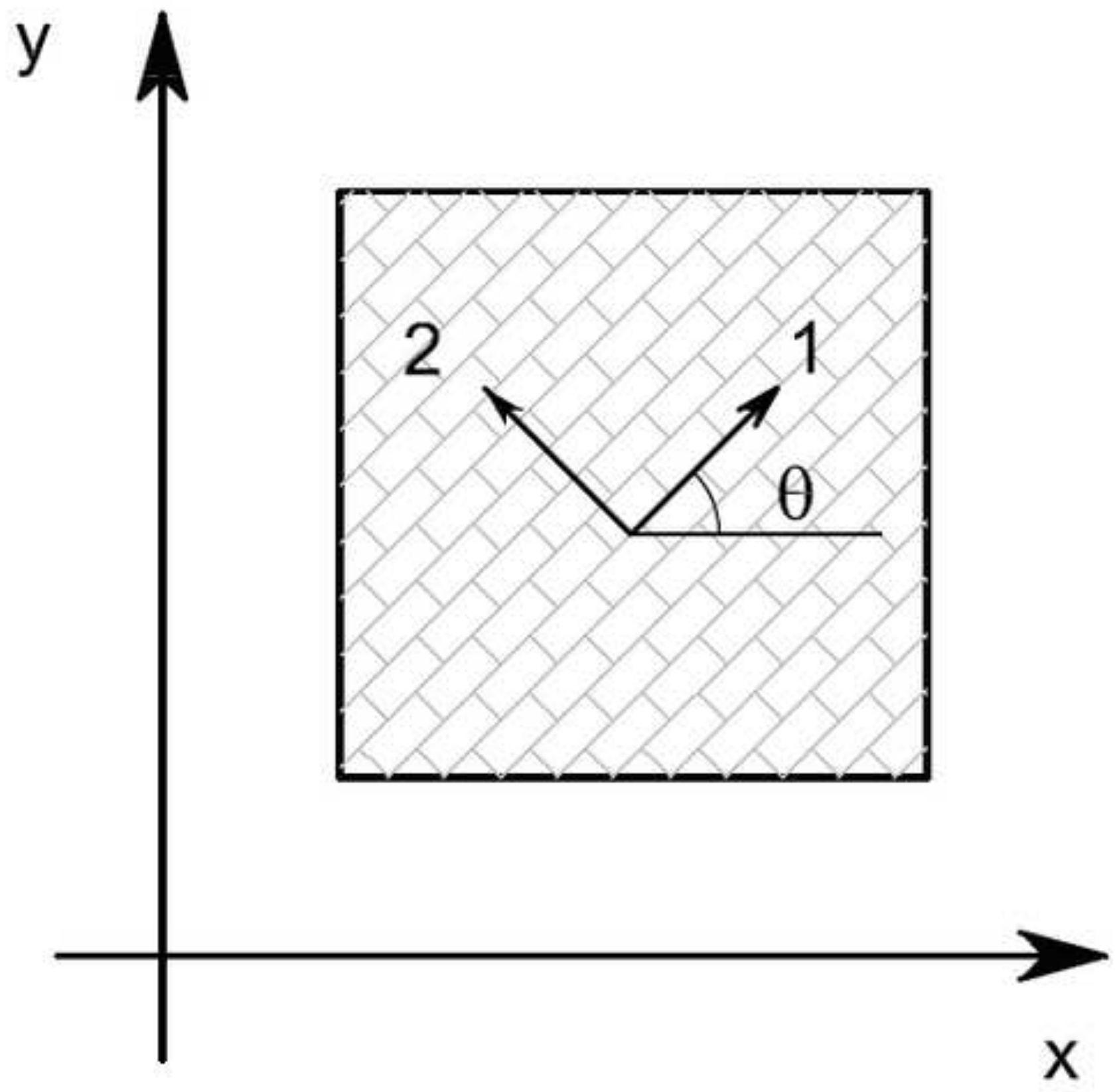


Click here to download high resolution image

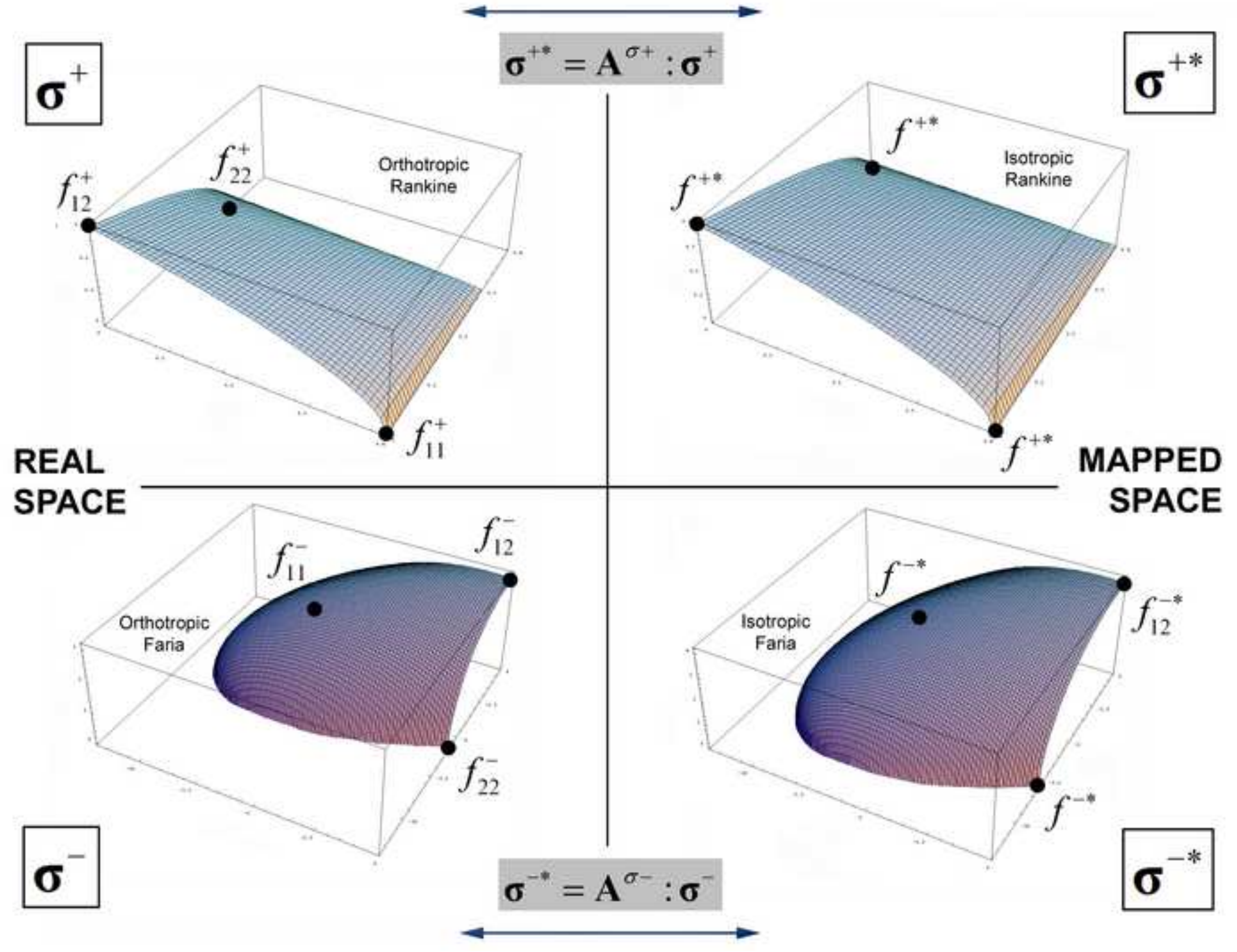




\section{Figure 4}

Click here to download high resolution image

(a)

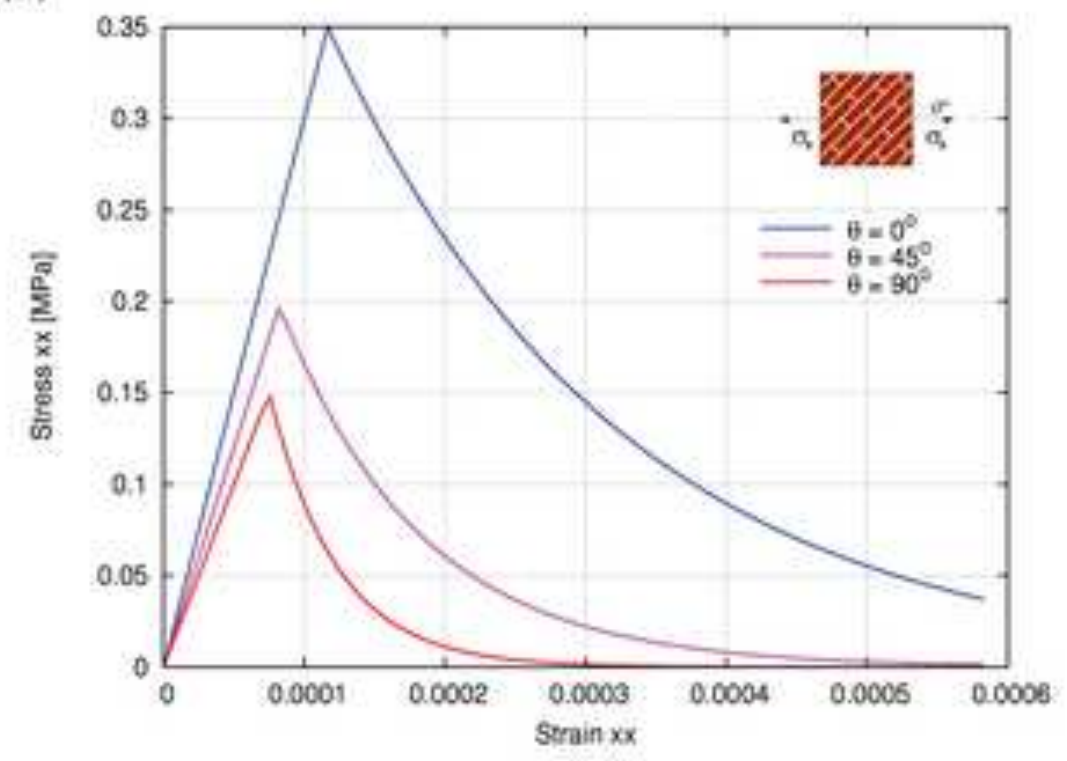

(b)

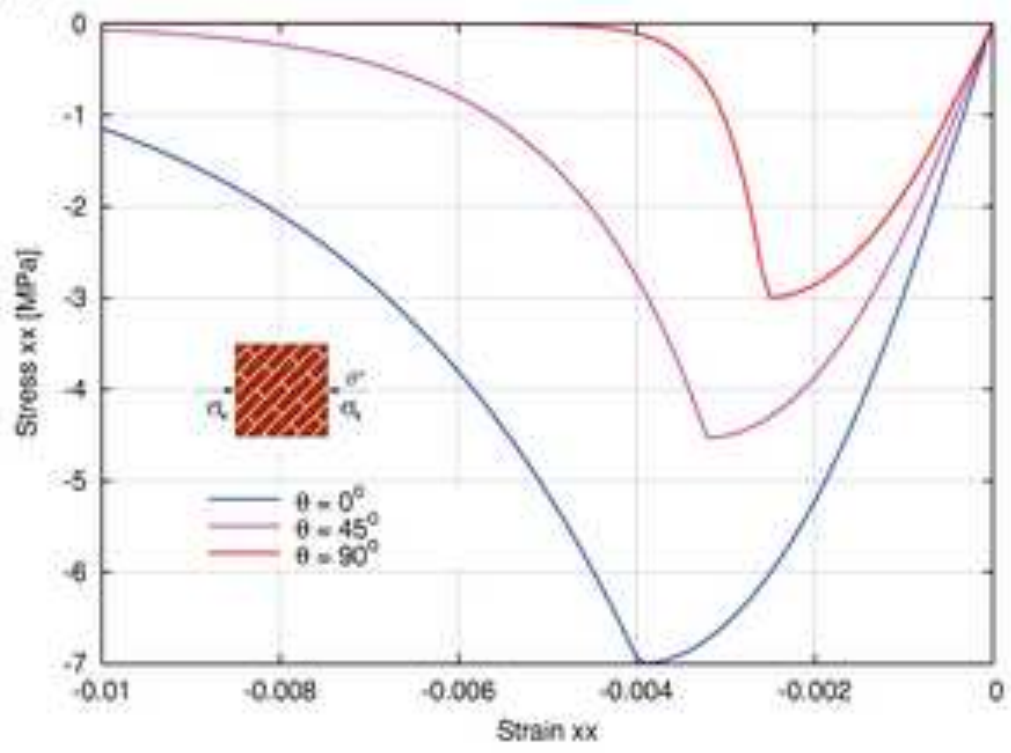

(c)

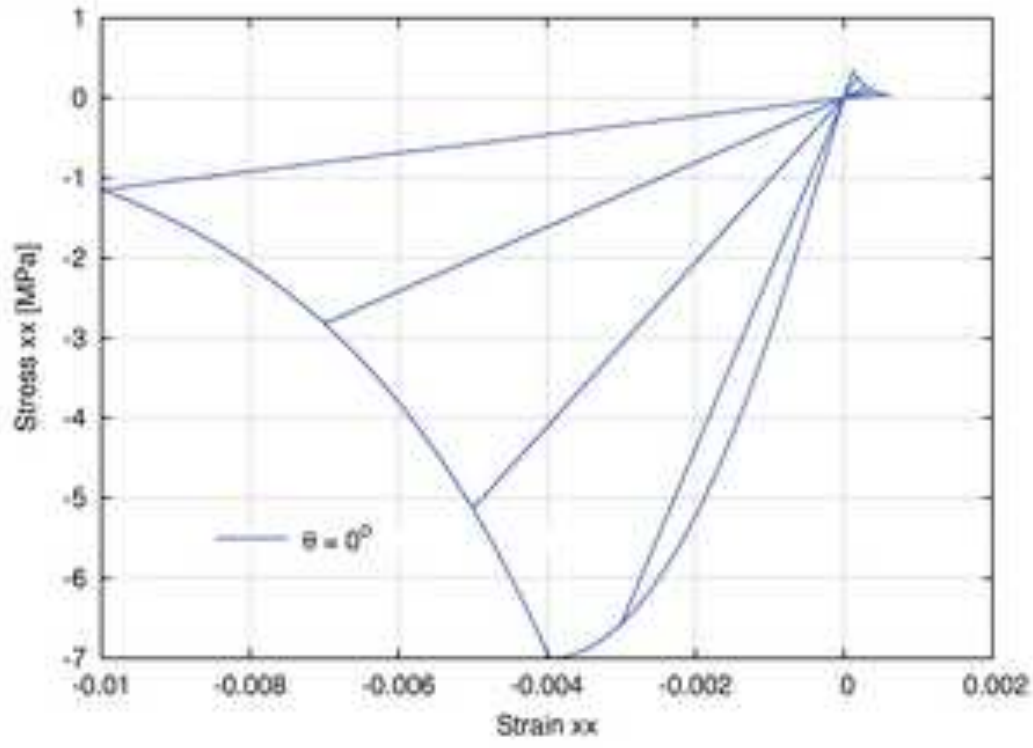


Click here to download high resolution image
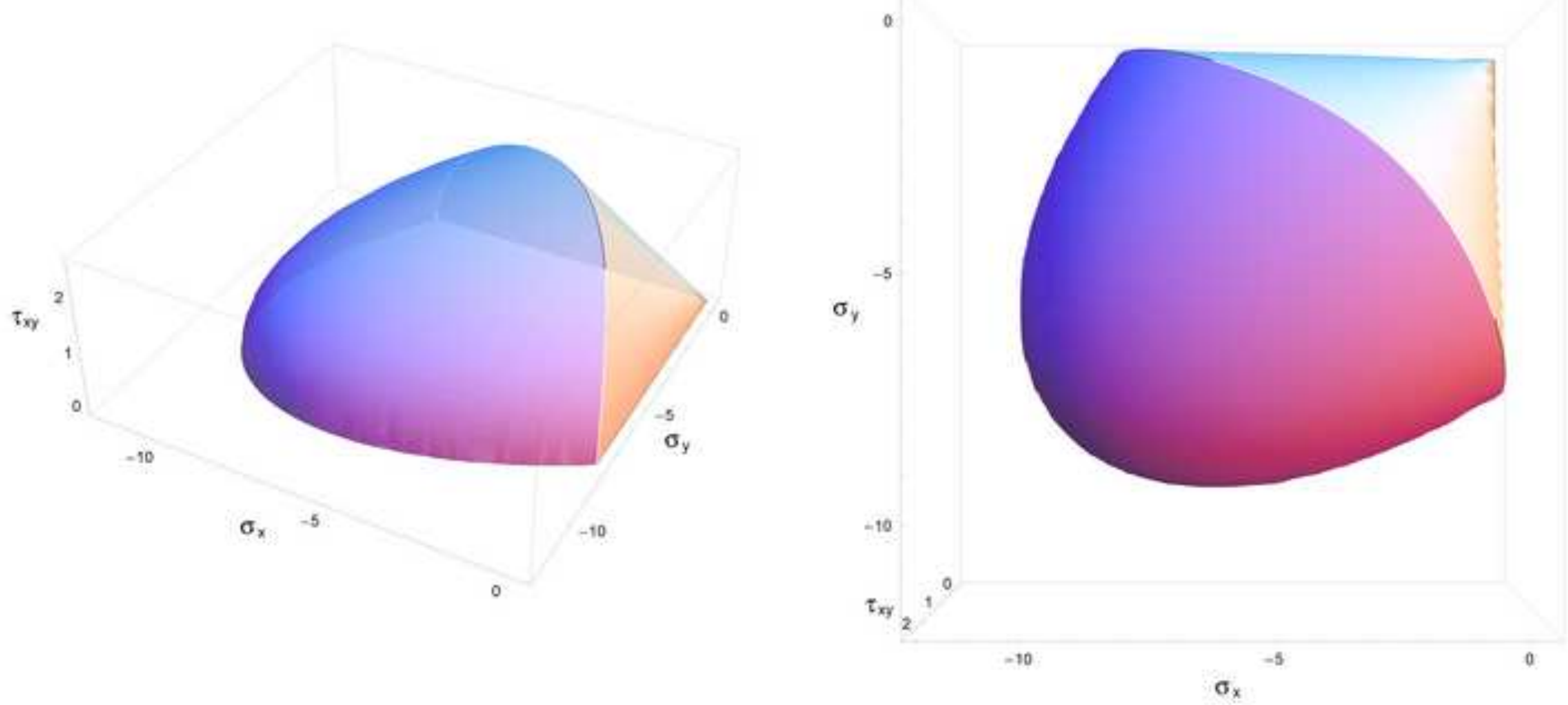
Click here to download high resolution image

(a)
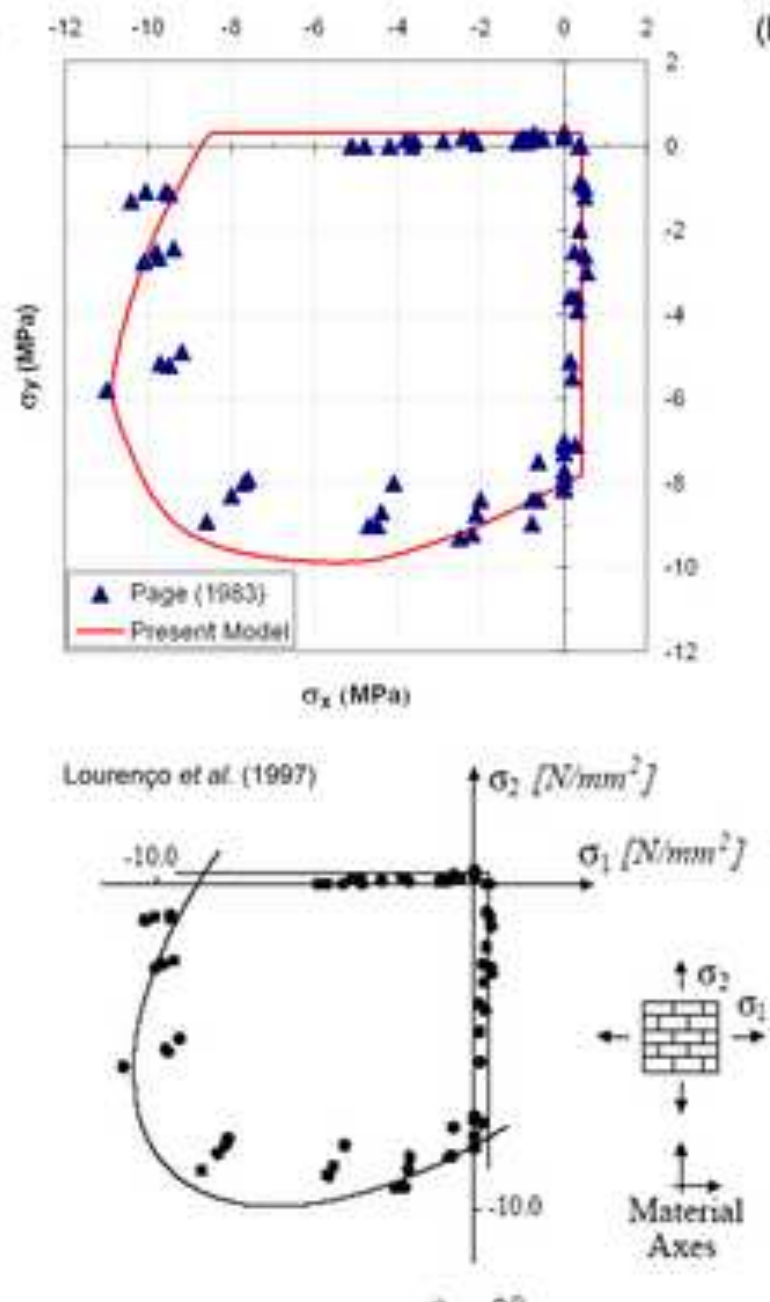

(b)

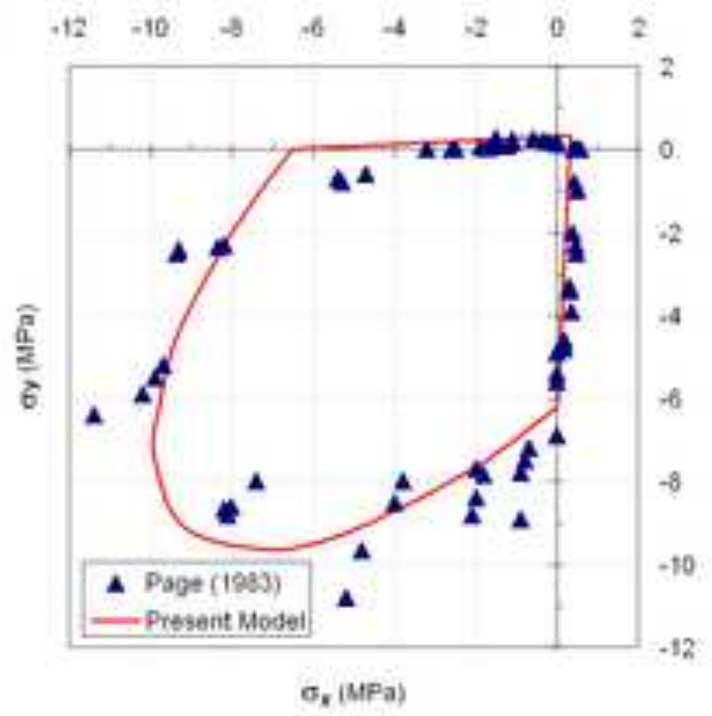

Loutenco et al itsen

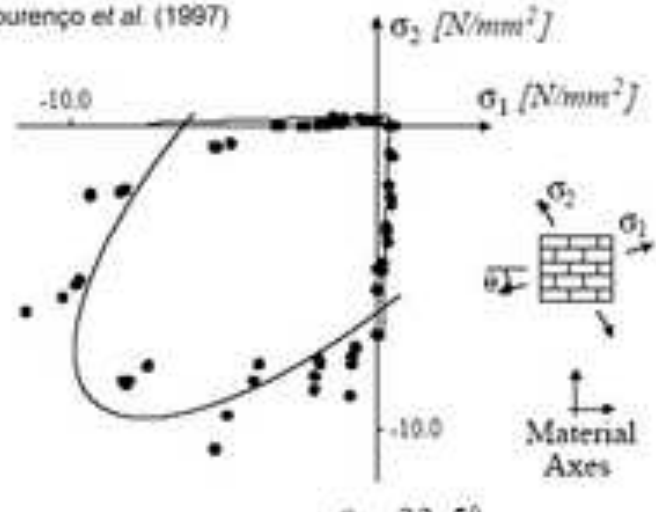

(c)

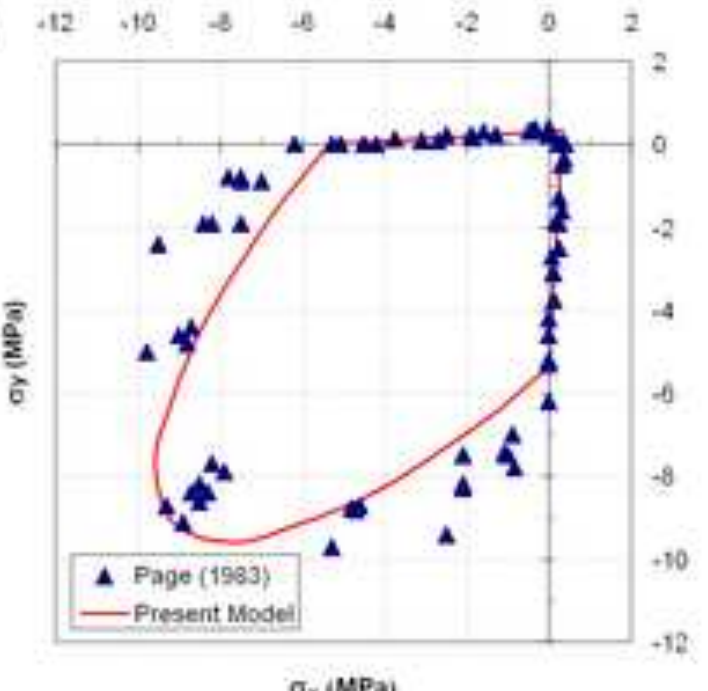

Lourenco of at (1907)

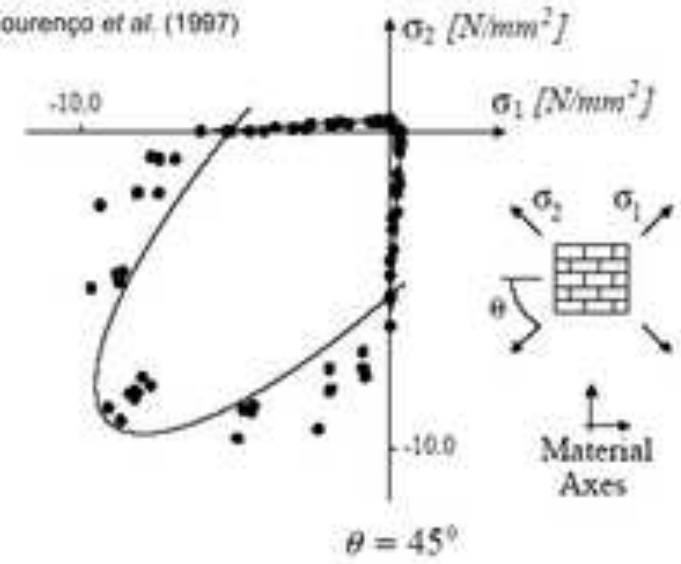


Figure 7
Click here to download high resolution image
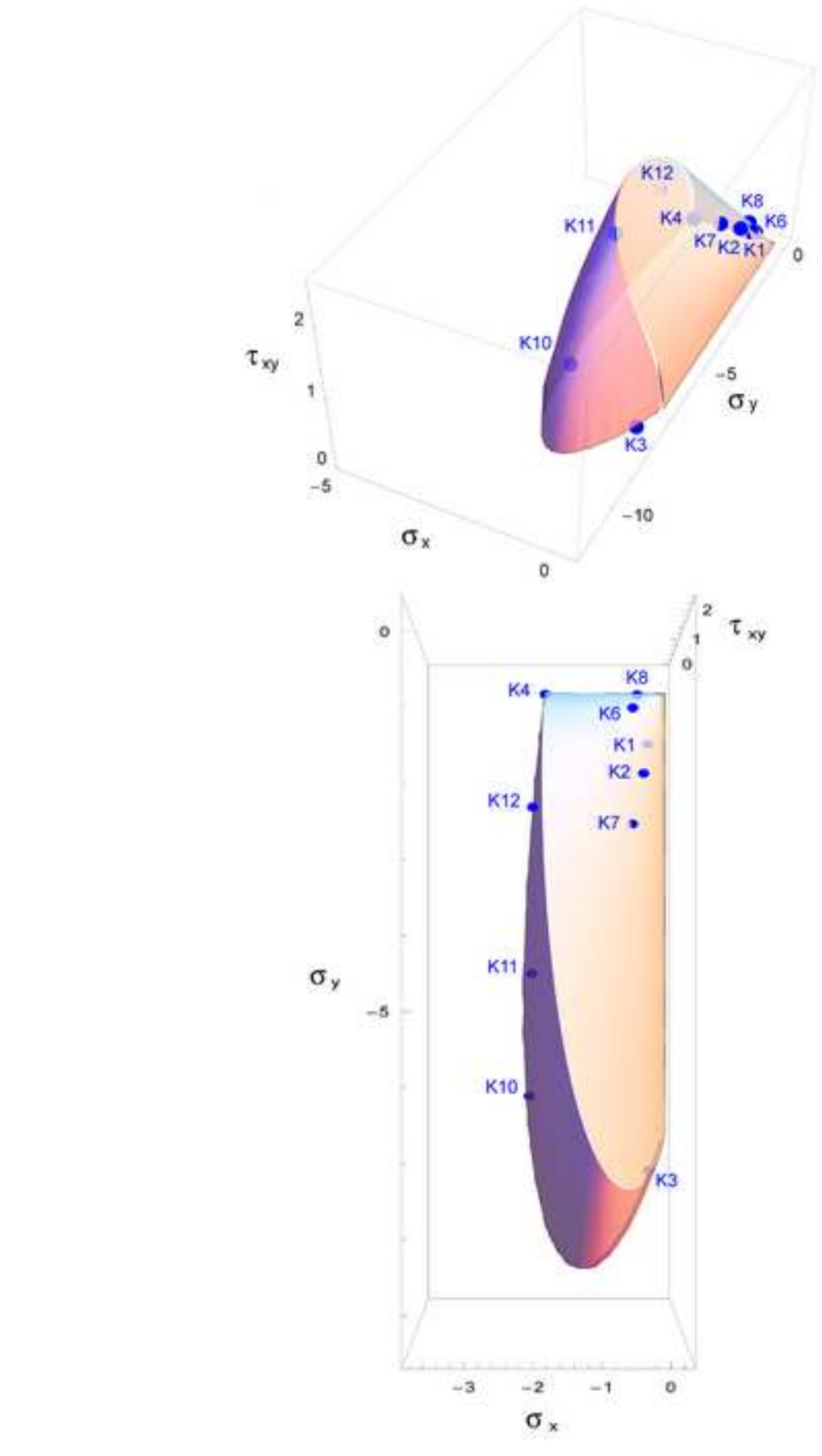
Click here to download high resolution image
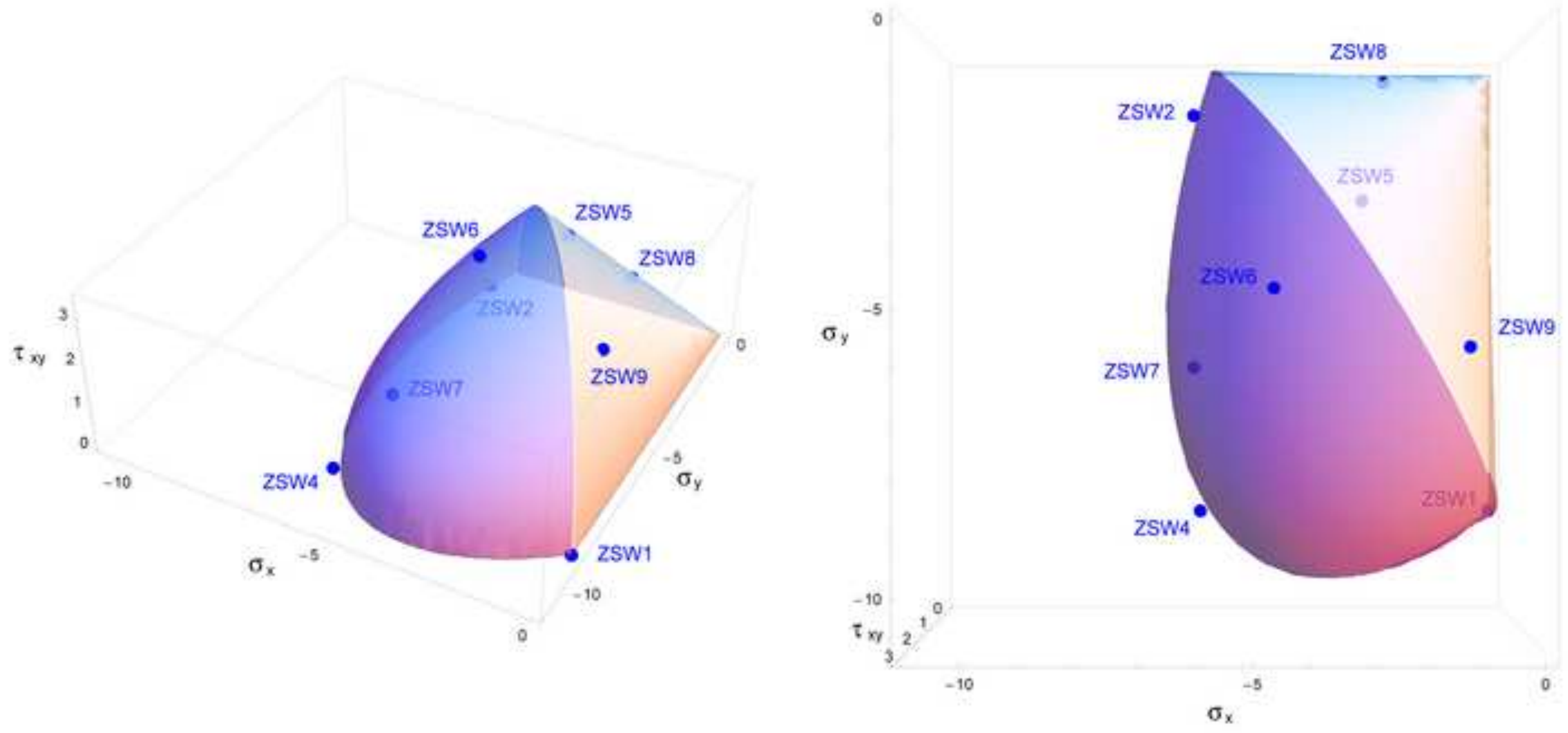
Click here to download high resolution image

(a)

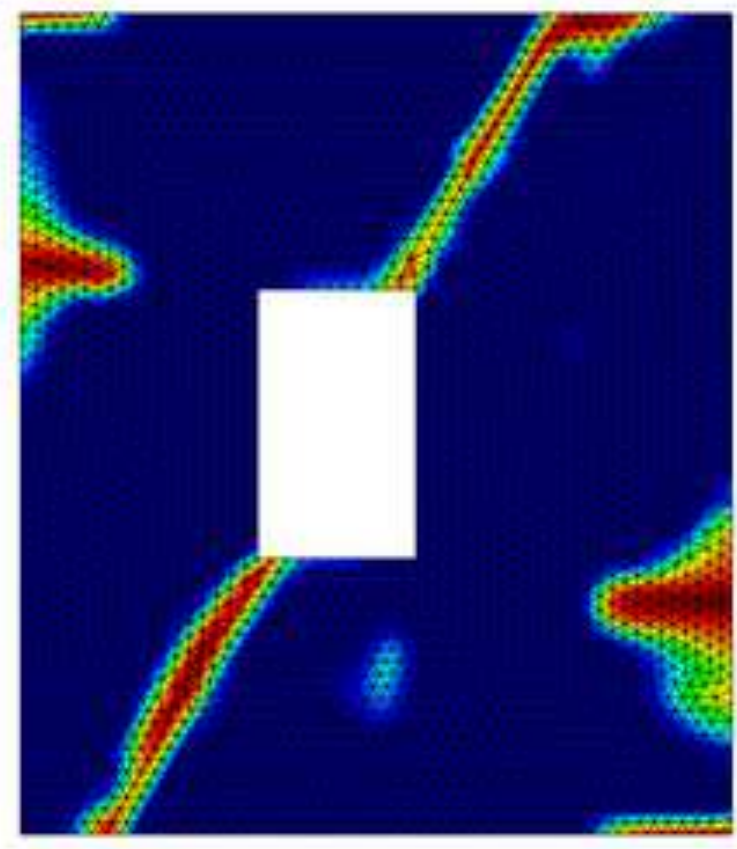

(c)

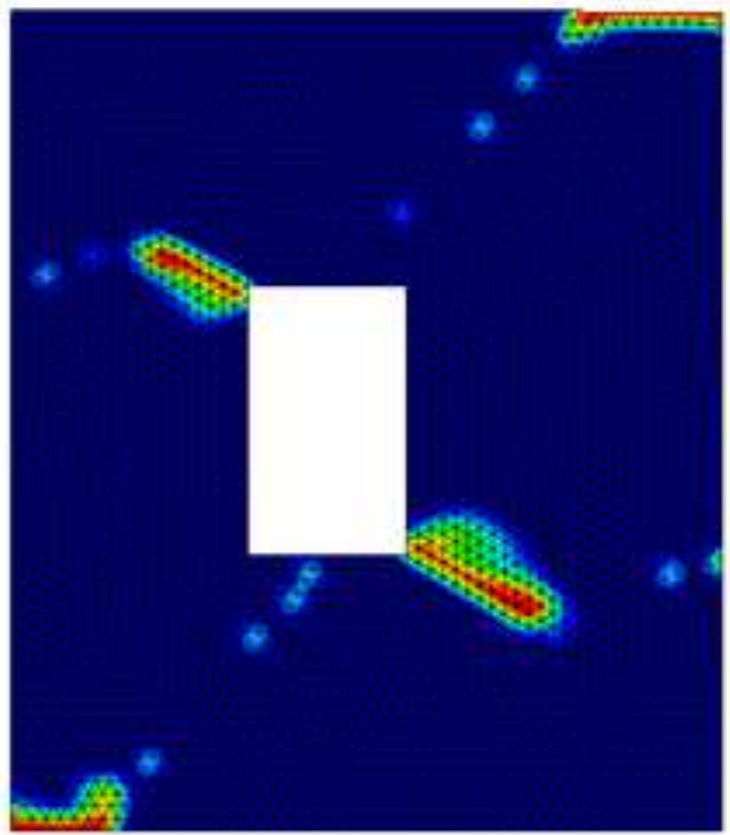

(b)

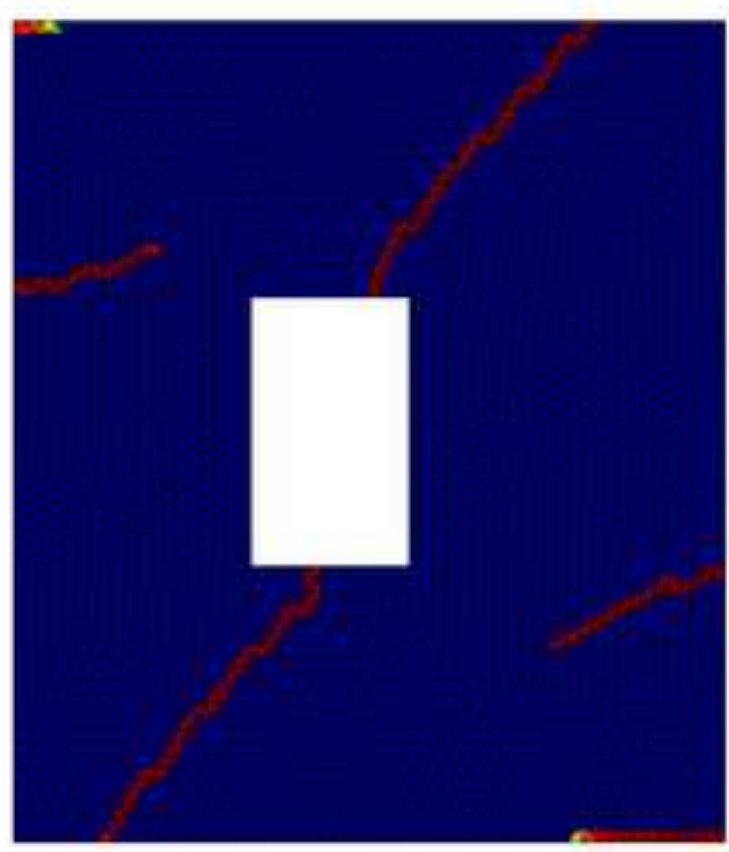

(d) cousmess puasice

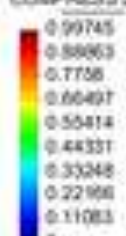
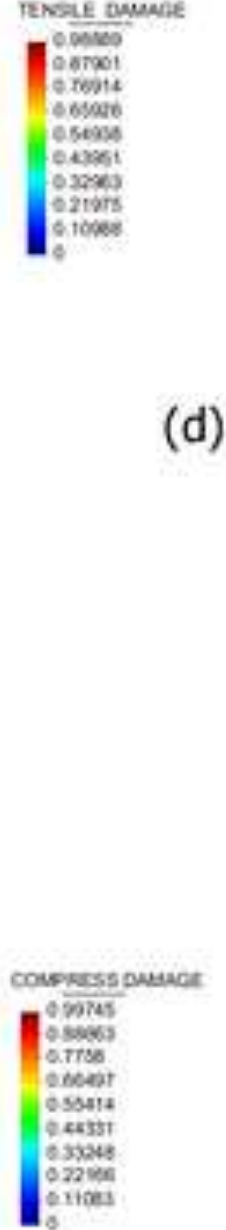

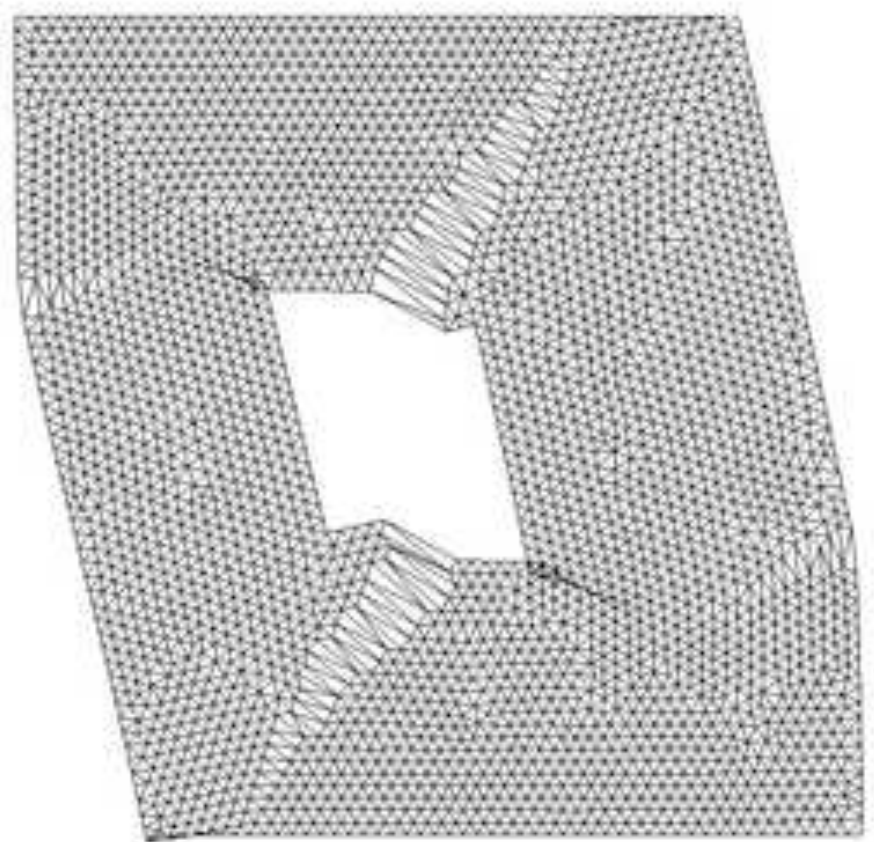




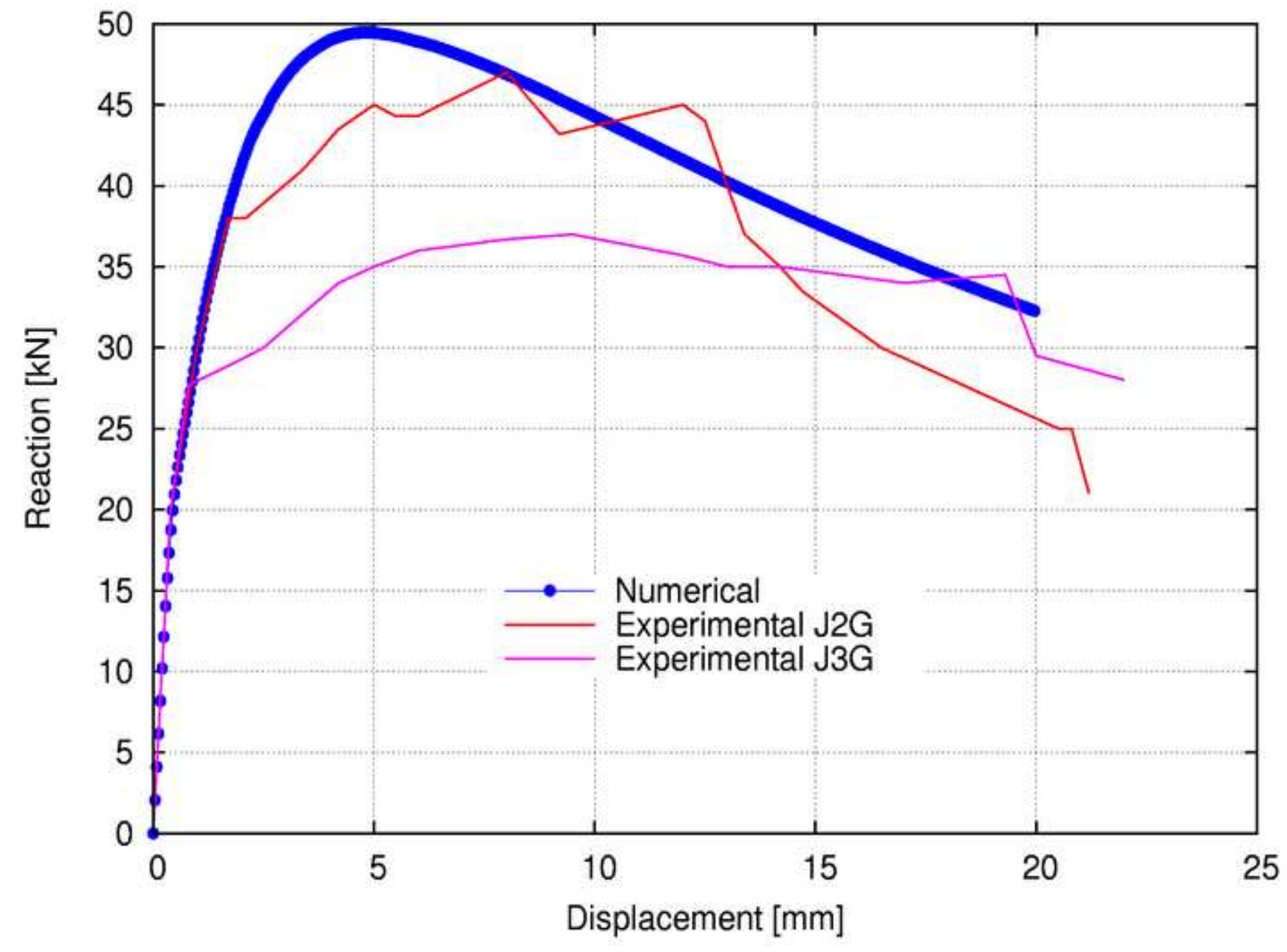




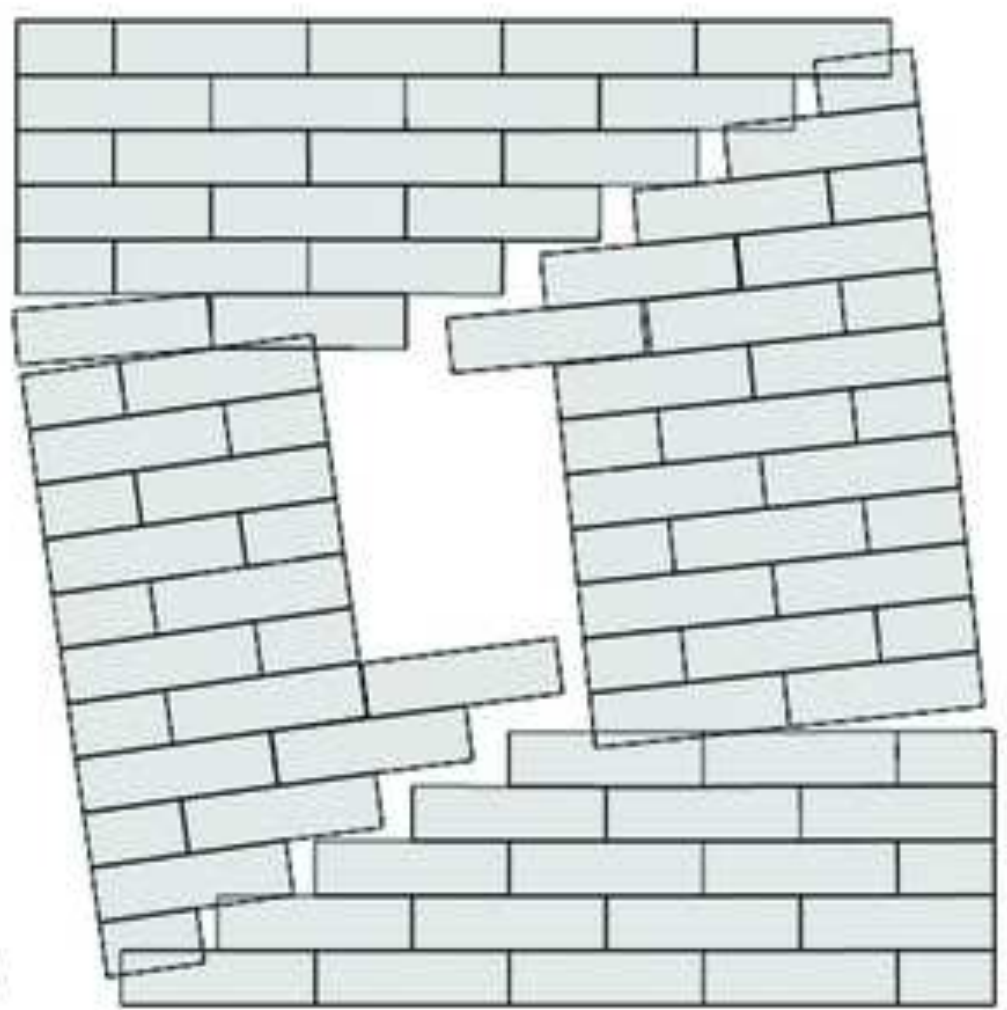

(b)

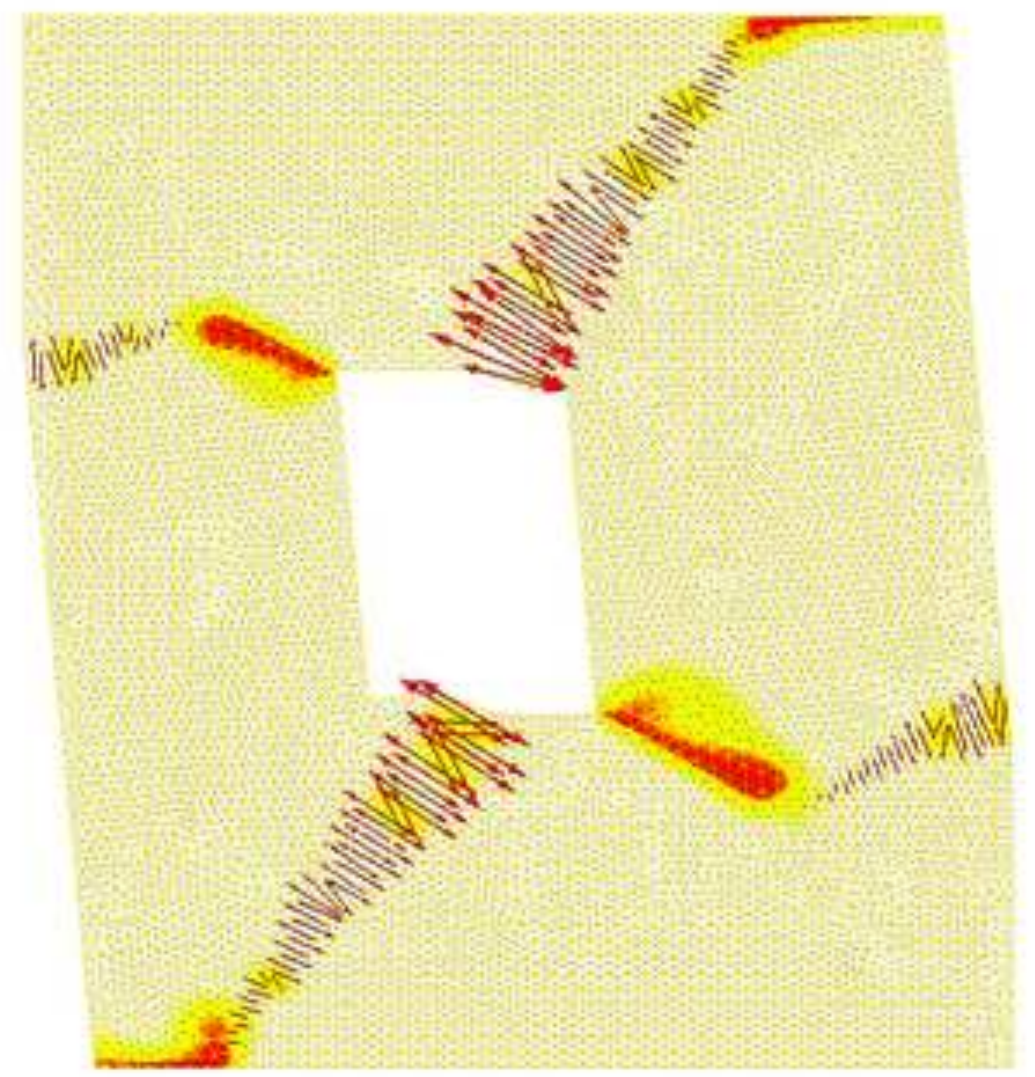

